\title{
Assessing the removal of organic micro-pollutants from anaerobic membrane bioreactor effluent by fertilizer-drawn forward osmosis
}

Youngjin $\mathrm{Kim}^{\mathrm{a}, \mathrm{b}}$, Sheng $\mathrm{Li}^{\mathrm{c}}$, Laura Chekli ${ }^{\mathrm{a}}$, Yun Chul $\mathrm{Woo}^{\mathrm{a}}$, Chun-Hai Wei ${ }^{\mathrm{c}}$, Sherub Phuntsho $^{\mathrm{a}}$, Noreddine Ghaffour ${ }^{\mathrm{c}}$, TorOve Leiknes ${ }^{\mathrm{c}}$, Ho Kyong Shon ${ }^{\mathrm{a}}$

${ }^{a}$ School of Civil and Environmental Engineering, University of Technology Sydney (UTS), Post Box 129, Broadway, NSW 2007, Australia

${ }^{\mathrm{b}}$ School of Civil, Environmental and Architectural Engineering, Korea University, 1-5 Ga, Anam-Dong, Seongbuk-Gu, Seoul, 136-713, Republic of Korea

${ }^{\mathrm{c}}$ King Abdullah University of Science and Technology (KAUST), Water Desalination and Reuse Center (WDRC), Division of Biological \& Environmental Science \& Engineering (BESE), Thuwal 23955-6900, Saudi Arabia

${ }^{*}$ Corresponding author. Tel.: +61-2-9514-2629; E-mail: Hokyong.Shon-1 @uts.edu.au

\begin{abstract}
In this study, the behavior of organic micro-pollutants (OMPs) transport including membrane fouling was assessed in fertilizer-drawn forward osmosis (FDFO) during treatment of the anaerobic membrane bioreactor (AnMBR) effluent. The flux decline was negligible when the FO membrane was oriented with active layer facing feed solution (AL-
\end{abstract}


FS) while severe flux decline was observed with active layer facing draw solution (AL-DS) with di-ammonium phosphate (DAP) fertilizer as DS due to struvite scaling inside the membrane support layer. DAP DS however exhibited the lowest OMPs forward flux or higher OMPs rejection rate compared to other two fertilizers (i.e., mono-ammonium phosphate (MAP) and $\mathrm{KCl}$ ). MAP and $\mathrm{KCl}$ fertilizer DS had higher water fluxes that induced higher external concentration polarization (ECP) and enhanced OMPs flux through the FO membrane. Under the AL-DS mode of membrane orientation, OMPs transport was further increased with MAP and $\mathrm{KCl}$ as DS due to enhanced concentrative internal concentration polarization while with DAP the internal scaling enhanced mass transfer resistance thereby lowering OMPs flux. Physical or hydraulic cleaning could successfully recover water flux for FO membranes operated under the AL-FS mode but only partial flux recovery was observed for membranes operated under AL-DS mode because of internal scaling and fouling in the support layer. Osmotic backwashing could however significantly improve the cleaning efficiency.

Keywords: Fertilizer-drawn forward osmosis, Fertigation, Anaerobic membrane bioreactor effluent, Organic micro-pollutants, Membrane fouling, Physical cleaning

\section{Nomenclature}

$A_{m} \quad$ Membrane area $\left(\mathrm{m}^{2}\right)$ 


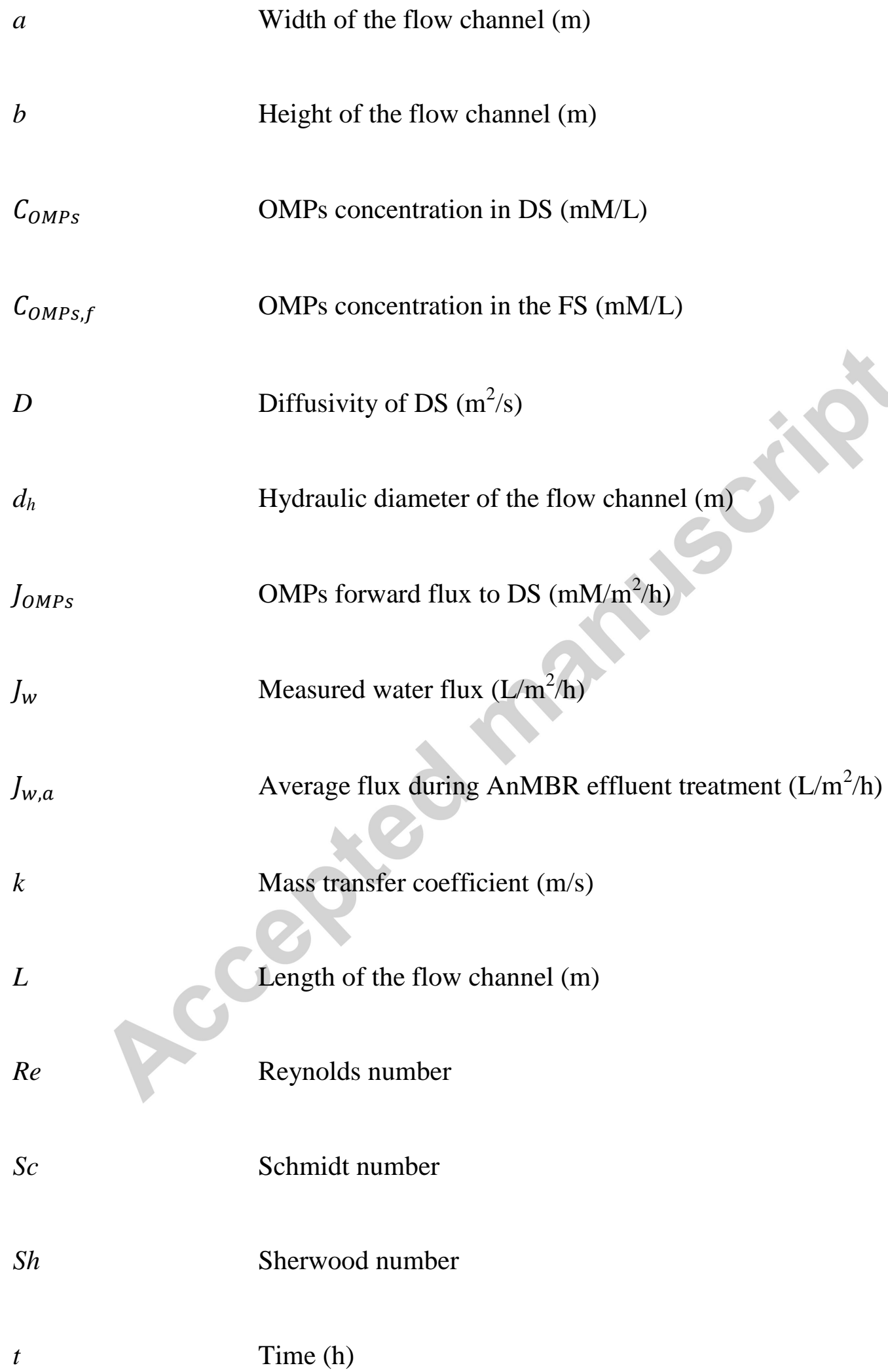




$\begin{array}{ll}V_{D f} & \text { Final volume of DS (L) } \\ V_{D i} & \text { Initial volume of DS (L) } \\ V_{p} & \text { Permeate volume (L) }\end{array}$

Greek symbol

$v$

Average crossflow rate $(\mathrm{m} / \mathrm{s})$

$v$

Kinematic viscosity $\left(\mathrm{m}^{2} / \mathrm{s}\right)$

Abbreviation

AL-DS

Active layer facing draw solution

AL-FS

Active layer facing feed solution

AnMBR

Anaerobic membrane bioreactor

CEOP

Cake-enhanced concentration polarization 
COD

CRCP

CTA

DAP

DI

DS

ECP

EDGs

EDX

EWGs

FDFO

FO

FS

HRT

ICP
Chemical oxygen demand

Cake-reduced concentration polarization

Cellulose triacetate

Di-ammonium phosphate

Deionized

Draw solution

External concentration polarization

Electron donating groups

Energy dispersive x-ray spectroscopy

Electron withdrawing groups

Fertilizer-drawn forward osmosis

Forward osmosis

Feed solution

Hydraulic retention time

Internal concentration polarization 


\begin{tabular}{|c|c|}
\hline MAP & Mono-ammonium phosphate \\
\hline NF & Nanofiltration \\
\hline OMPs & Organic micro-pollutants \\
\hline PPCPs & Pharmaceutical and personal care products \\
\hline PVDF & Polyvinylidene fluoride \\
\hline RO & Reverse osmosis \\
\hline SEM & Scanning electron microscopy \\
\hline TFC & Thin-film composite \\
\hline $\mathrm{TN}$ & Total nitrogen \\
\hline $\mathrm{TP}$ & Total phosphorous \\
\hline RSF & Reverse salt flux \\
\hline UF & Ultrafiltration \\
\hline XRD & X-Ray diffraction \\
\hline
\end{tabular}




\section{Introduction}

Freshwater scarcity is getting more severe due to the impacts of climate change, rapid population growth and extensive industrialization [1]. Furthermore, about $70 \%$ (global average) of the accessible freshwater is still consumed by the agricultural sector [2]. Particularly in water scarce regions, wastewater reuse in the agricultural sector can be very helpful in sustaining freshwater resources. Besides, treated wastewater can contribute to an appreciable amount of necessary nutrients for plants [3]. Therefore, the use of reclaimed water for agricultural irrigation has been reported in at least 44 countries [4]. For example, $30-43 \%$ of treated wastewater is used for agricultural and landscape irrigation in Tunisia [5]. In Australia, treated municipal wastewater of about $0.28 \times 10^{9} \mathrm{~m}^{3} /$ year is directly reused for irrigation [6]. However, wastewater reuse is often limited due to the presence of harmful heavy metals, industrial waste, pharmaceutical and personal care products (PPCPs), and excess salts. Organic micro-pollutants (OMPs), originating from PPCPs, herbicides and pesticides, and industry, could have potential harmful impacts on public health and the environment because of their bioaccumulation [7]. Therefore, OMPs should be effectively removed to enable reuse of wastewater for irrigation [8].

Anaerobic membrane bioreactors (AnMBR) have been studied for wastewater treatment as the treatment scheme has several advantages, including complete rejection of suspended solids, low sludge production, high organic rejection and biogas production [9]. 
Recent studies on the efficiency of OMPs removal in the AnMBR process indicated that bio-transformation is the dominant OMPs removal mechanism [10] and there is a correlation between hydrophobicity, specific molecular features (i.e., electron withdrawing groups (EWGs) and electron donating groups (EDGs)) and OMPs removal efficiency [11]. Especially, most readily biodegradable OMPs contain strong EDGs while most refractory OMPs contain strong EWGs or halogen substitute [12] . Besides, some OMPs can be captured by the fouling layer on the membrane surface thereby enhancing their removal efficiencies [13]. Even though OMPs can be biodegraded and removed by AnMBR, their removal rate is considered insufficient for direct reuse (e.g. non-potable applications such as fertigation) since some OMPs (e.g., atenolol, atrazine, TCEP, Primidone and caffeine) are hardly removed by AnMBR [11, 12].

For wastewater reuse advanced post-treatment processes (e.g., nanofiltration (NF), reverse osmosis (RO), forward osmosis (FO) or advanced oxidation) are often required to enhance the removal efficiency since most OMPs, even at very low concentration levels, may have a negative effect on the environment. Stand-alone NF can remove OMPs with their rejection rates from about $20 \%$ to almost $100 \%$ depending on their different characteristics (i.e., hydrophobicity and molecular shape) [14]. By combining AnMBR with NF, the OMPs removal efficiency can be improved up to $80-92 \%$ [12] . Furthermore, thin-film composite polyamide RO membranes have a 57 - 91\% rejection range for OMPs, which is lower than the salt rejection rate since OMPs are generally of low molecular size and are neutral compounds [15]. On the other hand, FO has a higher OMPs removal efficiency than RO since OMPs forward flux is likely hindered by the reverse solute flux 
(RSF) of the draw solute [16]. However, since FO utilizes highly concentrated DS as a driving force, additional desalting processes (e.g., NF, RO or membrane distillation) are required to extract pure water from DS [17].

Recently, fertilizer-drawn forward osmosis (FDFO) has received increased attention since the diluted fertilizer solution can be utilized directly for irrigation purpose and thus a separation and recovery process for the diluted DS is not required [18-20]. In the early studies, both single and blended fertilizers were investigated for direct application, however the diluted fertilizer solution still required substantial dilution as the final nutrient concentration exceed the standard nutrient requirements for irrigation, especially using feed water sources with high salinity $[18,19]$. For high salinity feed water, a NF process can be employed as a post-treatment for further dilution thereby meeting the water quality requirements for fertigation [21]. A pilot-scale FDFO and NF hybrid system was recently evaluated for 6 months in the field [22]. However, the energy consumption of the NF process is still a challenge for such a FDFO-NF hybrid system. Pressure-assisted fertilizerdrawn forward osmosis (PA-FDFO) is another suitable option for further enhancing final dilution of fertilizer DS beyond the point of osmotic equilibrium between DS and feed solution (FS) [23].

FDFO is viewed to be more suitable for the treatment of low salinity impaired water sources so that a desired fertilizer dilution can be achieved without the need of a NF posttreatment process. Recent reports have shown FDFO has been applied using commercial liquid fertilizers for the osmotic dilution of wastewater for fertigation of green walls [20, 24]. For both wastewater reuse and irrigation purposes, a novel FDFO-AnMBR hybrid 
system for a greenhouse hydroponic application was proposed and reported in our earlier study [25]. Despite the recent efforts to develop and understand FDFO for wastewater treatment [26], OMPs removal in FDFO has not yet been investigated, in particular the impact of fertilizer properties, fertilizer concentration and FO membrane orientation. Moreover, by combining FDFO with AnMBR, total OMPs removal rates can be significantly enhanced since FDFO can treat non-biodegradable OMPs from AnMBR.

The main objective of this study is therefore to investigate the feasibility of FDFO for treatment of AnMBR effluents with a particular emphasis on OMPs removal and membrane fouling. Atenolol, atrazine, and caffeine were utilized as representatives of OMPs due to their low removal propensity in AnMBR. The study also looked at how membrane fouling may be affected during the treatment of AnMBR effluents by FDFO as a function of types of fertilizer DS used in relation to their concentrations and thermodynamic properties and membrane orientation. Finally, the effect of membrane fouling on OMPs transport was also investigated.

\section{Materials and methods}

\subsection{FO membrane}

Cellulose triacetate (CTA) FO membranes embedded in a woven polyester mesh, provided by Hydration Technology Innovations, HTI (Albany, OR, USA), was used in this study. The detail characteristics of this commercial membrane can be found elsewhere [27, 28]. 


\subsection{Feed solution}

AnMBR effluent used for FDFO treatment was collected from a lab-scale AnMBR system. The lab-scale AnMBR system consisted of a commercial anaerobic stirred tank reactor (CSTR, Applikon Biotechnology, Netherland) with an effective volume of 2 L and a side-stream hollow-fiber polyvinylidene fluoride (PVDF) ultrafiltration (UF) membrane with a nominal pore size of $30 \mathrm{~nm}[12,29]$. The recipe of synthetic wastewater with chemical oxygen demand (COD) of $800 \mathrm{mg} / \mathrm{L}$ used in this system can be found elsewhere [29]. The operational conditions of this system were as follows: temperature $35 \pm 1{ }^{\circ} \mathrm{C}, \mathrm{pH}$ $7 \pm 0.1$, stirring speed $200 \pm 2 \mathrm{rpm}, \mathrm{MBR}$ water flux of $3 \mathrm{~L} / \mathrm{m}^{2} / \mathrm{h}$ and hydraulic retention time (HRT) of $24 \mathrm{~h}$. For all the FDFO experiments in this study, AnMBR effluent was collected every day for 2 weeks, mixed together and stored in a refrigerator at $4{ }^{\circ} \mathrm{C}$ to obtain a homogeneous feed water composition throughout the study. Detail information of AnMBR effluent used as feed in this study is provided in Table 1.

Table 1. Water quality of anaerobic membrane bioreactor effluent used in this study. The analysis was conducted repeatedly.

\begin{tabular}{cccc}
\hline Components & Values & Components & Values \\
\hline COD $(\mathrm{ppm})$ & $57.15( \pm 9.12)$ & $\mathrm{K}^{+}(\mathrm{ppm})$ & $11.78( \pm 2.69)$ \\
Conductivity & $1.68( \pm 0.28)$ & $\mathrm{Na}^{+}(\mathrm{ppm})$ & $23.5( \pm 3.27)$ \\
$(\mathrm{mS} / \mathrm{cm})$ & & & \\
$\mathrm{TP}(\mathrm{ppm} \mathrm{PO}-\mathrm{P})$ & $32.19( \pm 2.97)$ & $\mathrm{Mg}^{2+}(\mathrm{ppm})$ & $3.95( \pm 0.57)$ \\
\hline
\end{tabular}




\begin{tabular}{|c|c|c|c|}
\hline $\mathrm{TN}(\mathrm{ppm} \mathrm{N})$ & $84.75( \pm 13.79)$ & $\mathrm{Cl}^{-}(\mathrm{ppm})$ & $9.21( \pm 1.42)$ \\
\hline Turbidity & $0.77( \pm 0.02)$ & $\mathrm{SO}_{4}^{2-}(\mathrm{ppm})$ & $1.04( \pm 0.14)$ \\
\hline $\mathrm{pH}$ & $8( \pm 0.13)$ & & \\
\hline
\end{tabular}

Three different OMPs (Atenolol, Atrazine and Caffeine), received in powder form from Sigma Aldrich (Saudi Arabia), were used as representative OMPs since they are generally found in wastewater but not readily removed in AnMBR [12]. Atenolol and atrazine contain both EDGs and EWGs and are therefore possible refractory compounds, and also caffeine has a low removal rate at the initial stage due to its prolonged adaption time even though caffeine has a strong EDG, which is supported by experimental results [12] . Their key properties are provided in Table 2. Stock solution with a final concentration of $3 \mathrm{~g} / \mathrm{L}$ (i.e., $1 \mathrm{~g} / \mathrm{L}$ for each OMP) was prepared by dissolving $3 \mathrm{mg}$ of OMP compounds (i.e., $1 \mathrm{mg}$ for each OMP) in $1 \mathrm{~mL}$ of pure methanol. The stock solution was then stored in a refrigerator at $4^{\circ} \mathrm{C}$ prior to the experiments.

Table 2. Physicochemical properties of OMPs used in this study

Atenolol Atrazine Caffeine




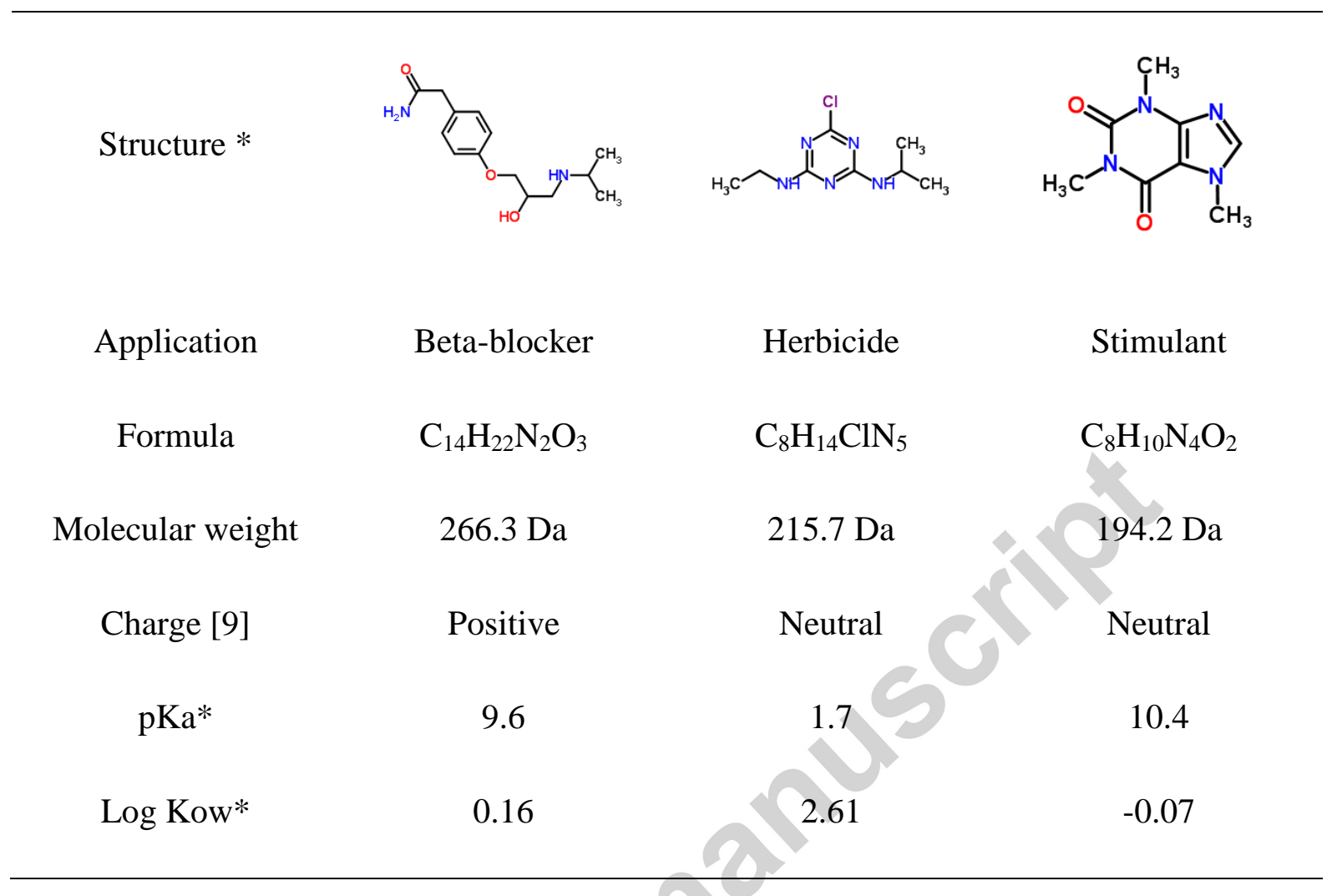

* Data from ChemSpider website (http://www.chemspider.com).

\subsection{Draw solutions}

Three different chemical fertilizers of reagent grade were used in this study (Sigma Aldrich, Saudi Arabia) and they consisted of mono-ammonium phosphate (MAP), diammonium phosphate (DAP) and potassium chloride $(\mathrm{KCl})$. DS was prepared by dissolving fertilizers in deionized (DI) water. Detailed information of fertilizer chemicals is provided in Table S1. Osmotic pressure, diffusivity and viscosity of three fertilizers were obtained by OLI Stream Analyzer 3.2 (OLI System Inc., Morris Plains, NJ, USA). 


\subsection{FDFO experiments}

\subsubsection{Lab-scale FO system}

All FDFO experiments were carried out using a lab-scale FO system similar to the one described in our previous studies [27, 30]. The FO cell had two symmetric channels (i.e., $100 \mathrm{~mm}$ long, $20 \mathrm{~mm}$ wide and $3 \mathrm{~mm}$ deep) on both sides of the membrane each fed with FS and DS respectively. Variable speed gear pumps (Cole-Parmer, USA) were used to provide crossflows under co-current directions at a crossflow rate of $8.5 \mathrm{~cm} / \mathrm{s}$. Solution temperature was $20^{\circ} \mathrm{C}$. Both solutions were recirculated in a closed-loop system resulting in a batch mode process operation. The DS tank was placed on a digital scale and the weight changes were recorded by a computer in real time every 3 mins interval to determine the water flux.

\subsubsection{AnMBR effluent treatment by FDFO}

FDFO experiments were carried out under either AL-FS (i.e., active layer facing FS) or AL-DS (i.e., active layer facing DS) modes at $1 \mathrm{M}$ or $2 \mathrm{M}$ fertilizer DS concentrations. Detailed descriptions of FO experiments are available elsewhere [27, 30, 31]. Crossflow velocities of DS and FS were set at $8.5 \mathrm{~cm} / \mathrm{s}$ and temperature at $20^{\circ} \mathrm{C}$. For FDFO performance experiments, DI water was utilized as FS with fertilizer DS. In order to investigate the OMPs transport behaviors in FDFO during AnMBR effluent treatment, prior to all experiments, $10 \mu \mathrm{L}$ of OMPs stock solution was spiked into 1 L FS (i.e., AnMBR effluent) to obtain a final concentration of $10 \mu \mathrm{g} / \mathrm{L}$ each of the three OMPs, giving a total of $30 \mu \mathrm{g} / \mathrm{L}$ [12] . For understanding OMPs transport behavior, average water flux during FDFO experiments was obtained and compared with OMPs forward flux. 


$$
J_{w, a}=\frac{V_{p}}{A_{m} t}=\frac{V_{D f}-V_{D i}}{A_{m} t}
$$

where, $J_{w, a}$ is the average flux during AnMBR effluent treatment $\left(\mathrm{L} / \mathrm{m}^{2} / \mathrm{h}\right), V_{p}$ is the permeate volume (L), $V_{D i}$ is the initial volume of DS (L), $V_{D f}$ is the final volume of DS (L), $A_{m}$ is the membrane area $\left(\mathrm{m}^{2}\right)$, and $\mathrm{t}$ is time $(\mathrm{h})$. Mass transfer coefficients were further obtained to elucidate the FO performance in terms of water flux and physical cleaning efficiency. Firstly, Reynolds number was determined by Eqn. (2) to see whether the type of flow in the channel is laminar or turbulent. Then, Schmidt number and hydraulic diameter (for fully filled rectangular duct) were obtained based on Eqns. (3) and (4), respectively. By using Reynolds number, Schmidt number and hydraulic diameter, Sherwood number was calculated as Eqns. (5) or (6) for laminar or turbulent flows in fully filled rectangular duct, and thus a mass transfer coefficient could be lastly obtained as Eqn. (7).

$$
\begin{gathered}
R e=\frac{v d_{h}}{v} \\
S c=\frac{v}{D} \\
d_{h}=\frac{2 a b}{a+b} \\
S h=1.85\left(R e \cdot S c \cdot d_{h} / L\right)^{0.33} \\
S h=0.04 R e^{0.75} \cdot S c^{0.33} \\
k=\frac{S h \cdot D}{d_{h}}
\end{gathered}
$$

where, $R e$ is Reynolds number, $S c$ is Schmidt number, $d_{h}$ is the hydraulic diameter of the flow channel $(\mathrm{m}), S h$ is Sherwood number, $k$ is mass transfer coefficient $(\mathrm{m} / \mathrm{s}), v$ is the average crossflow rate $(\mathrm{m} / \mathrm{s}), a$ is the width of the flow channel $(\mathrm{m}), b$ is the height of the 
flow channel (m), $D$ is diffusivity of DS $\left(\mathrm{m}^{2} / \mathrm{s}\right), v$ is kinematic viscosity $\left(\mathrm{m}^{2} / \mathrm{s}\right)$, and $L$ is the length of the flow channel (m). Since draw solution is gradually diluted during FDFO operation, osmotic pressure difference was reduced during FDFO experiments. To evaluate the effect of membrane fouling only on flux decline, a baseline test was carried out for $10 \mathrm{~h}$ with DI water as feed solution prior to each experiment (Fig. S1) and the resulting flux curves were utilized as a baseline to correct the flux curves obtained [27].

\subsubsection{Physical cleaning}

In order to investigate the effect of physical (or hydraulic) cleaning on flux recovery, two different physical cleaning methods were adopted for all FDFO experiments. Osmotic backwashing was however investigated only for those experiments conducted under the AL-DS mode. Physical cleaning consisted of flushing DI water inside the DS and FS channels at 3 times higher crossflow velocity $(25.5 \mathrm{~cm} / \mathrm{s})$ for $30 \mathrm{mins}$. Osmotic backwashing was conducted for 30 mins by flushing $1 \mathrm{M} \mathrm{NaCl}$ solution on the support layer side of the membrane and DI water on the active layer side (both at $8.5 \mathrm{~cm} / \mathrm{s}$ crossflow velocity) in order to provide water flux in reverse direction to the experiment conducted under AL-DS mode of membrane orientation. After each physical cleaning, baseline FDFO experiments were conducted using fertilizers DS and DI FS to evaluate the water flux recovery rate.

\subsection{Analytical methods for organic micro-pollutants}

OMPs in samples were analyzed following the procedures described in previous studies $[12,32] .100 \mathrm{~mL}$ samples were prepared and spiked with the corresponding isotopes (Cambridge Isotope Laboratories, Inc., USA) as the internal standards to measure the 
recovery ratio during the following extraction and evaporation process. OMPs samples were first extracted via solid phase extraction (Dione Autotrace 280 solid-phase extraction instrument and Oasis cartridges) and then concentrated via evaporation. OMPs concentration was then measured by liquid chromatography (Agilent Technology 1260 Infinity Liquid Chromatography unit, USA) connected to mass spectrometry (AB SCIEX QTRAP 5500 mass spectrometer, Applied Biosystems, USA) and each concentration was calculated by comparing its peak area with the peak area of the corresponding isotope (i.e., fixed concentration). OMPs forward flux to DS can be obtained based on mass balance for OMPs species [33, 34].

As the initial OMPs concentration in DS is zero, OMPs mass balance yields:

$$
C_{O M P S}\left(V_{D i}+J_{w} A_{m} t\right)=J_{O M P S} A_{m} t
$$

where, $C_{O M P S}$ is the OMPs concentration in DS $(\mathrm{mM} / \mathrm{L}), J_{w}$ is the measured water flux $\left(\mathrm{L} / \mathrm{m}^{2} / \mathrm{h}\right)$, and $J_{O M P S}$ is the OMPs forward flux to DS $\left(\mathrm{mM} / \mathrm{m}^{2} / \mathrm{h}\right)$. For OMPs forward flux, Eqn. (8) can be modified as:

$$
J_{O M P S}=\frac{C_{O M P S}\left(V_{D i}+J_{w} A_{m} t\right)}{A_{m} t}=\frac{C_{O M P S} V_{D f}}{A_{m} t}
$$

OMPs rejection in FDFO can be calculated by using the permeate concentration, yielding [35]:

$$
R_{O M P S}=\left(1-\frac{C_{O M P S}}{C_{O M P S, f}}\right) \times 100 \%
$$

where, $C_{O M P S, f}$ is the OMPs concentration in the $\mathrm{FS}(\mathrm{mM} / \mathrm{L})$. 


\subsection{Characterization of the membrane surface}

Membrane surface characterization was conducted by collecting membrane coupons after experiments, soaking them in DI water for a few seconds to remove FS and DS, and then dried in a desiccator for 1 day. The surface and cross-sectional morphologies of the FO membrane were observed and analyzed by scanning electron microscopy (SEM, Zeiss Supra 55VP, Carl Zeiss AG, Germany) and energy dispersive X-ray spectroscopy (EDX) following the procedures described in a previous study [36]. Samples taken from each membrane were first lightly coated with $\mathrm{Au} / \mathrm{Pd}$ and then the SEM imaging was carried out at an accelerating voltage of $10 \mathrm{kV}$.

X-Ray diffraction (XRD) (Siemens D5000, USA) analysis was also performed over Bragg angles ranging from $10^{\circ}$ to $60^{\circ}(\mathrm{Cu} \mathrm{K \alpha}, \lambda=1.54059 \AA)$ to investigate the dominant species responsible for scaling on the membrane surface.

Contact angles of fouled FO membranes were measured by the sessile drop method using an optical subsystem (Theta Lite 100) integrated with an image-processing software following the procedures described in a previous study [37]. Membrane samples were placed on a platform, and DI water droplets of $10 \mu \mathrm{L}$ were dropped automatically on the membrane surface. A real-time camera captured the image of the droplet, and the contact angle was estimated by a computer. At least 3 measurements were taken for each membrane sample and the average value was used.

\section{Results and discussion}




\subsection{AnMBR effluent treatment by FDFO}

\subsubsection{Basic FDFO performance: Water flux and reverse salt flux}

Three different fertilizers (MAP, DAP and $\mathrm{KCl}$ ) were selected as DS for this study. MAP and DAP are composed of the same components ( $\mathrm{N}$ and $\mathrm{P}$ ) but have different thermodynamic properties such as osmotic pressure and diffusivity while $\mathrm{KCl}$ has a different composition but has a similar osmotic pressure with MAP [25]. As shown in Table 3, MAP exhibited similar water flux with DAP under the AL-FS mode, even though DAP has higher osmotic pressure. This is due to lower diffusivity of DAP species which enhances the internal concentration polarization (ICP) effects that lowers the water flux [27]. However, under the AL-DS mode, DAP exhibited higher water flux than MAP due to less pronounced effects on ICP [17].

$\mathrm{KCl}$ showed a much higher water flux than MAP under all experiments despite having similar osmotic pressures, which is attributed to the higher diffusivity of $\mathrm{KCl}$ that lowers ICP effects under the AL-FS mode of operation. $\mathrm{KCl}$ also shows higher water flux compared to MAP under the AL-DS mode even though ICP effect should have been eliminated for both DS since DI water was used as FS in the support layer side of the membrane. This higher water flux of $\mathrm{KCl}$ is related to the higher mass transfer coefficient (i.e., $1.33 \times 10^{-5} \mathrm{~m} / \mathrm{s}$ and $1.01 \times 10^{-5} \mathrm{~m} / \mathrm{s}$ for $\mathrm{KCl}$ and MAP, relatively) compared to MAP that results in lower dilutive $\mathrm{ECP}$ effects. The $\mathrm{KCl}$ has higher diffusivity and lower viscosity compared to the MAP that significantly enhances its mass transfer coefficient (refer Table S1). The mass transfer coefficient of the draw solute depends on the average 
solute diffusivity and solution viscosity, assuming that the other operating conditions were similar for both $\mathrm{KCl}$ and MAP.

The performance of the three fertilizer DS was also investigated in terms of RSF. $\mathrm{KCl}$ showed the highest RSF in all cases probably due to its highest solute diffusivity and also lower hydrated diameters of both $\mathrm{K}^{+}$and $\mathrm{Cl}^{-}$species [38]. Interestingly, DAP showed much higher RSF than MAP even though they have similar components and DAP has much lower diffusivity as shown in Table 3. This can probably be explained due to the differences in their species formed in the water with DAP and MAP. Speciation analysis was carried out for $1 \mathrm{M}$ DAP and $1 \mathrm{M}$ MAP using OLI Stream Analyzer and their data is presented in Table S2, where the three major species $\left(\mathrm{NH}_{4}{ }^{+}, \mathrm{H}_{2} \mathrm{PO}_{4}^{-}\right.$and $\left.\mathrm{NH}_{3}\right)$ are considered to be of particular interest for comparison. It can be seen that 1 M DAP DS contains about $1.974 \mathrm{M} \mathrm{NH}_{4}{ }^{+}$compared to $1.0 \mathrm{M} \mathrm{NH}_{4}{ }^{+}$for MAP DS. This is one potential reason why the RSF of $\mathrm{NH}_{4}{ }^{+}$for DAP was observed to be higher than MAP in Table S2. Besides, $1 \mathrm{M}$ DAP DS also contains $0.026 \mathrm{M} \mathrm{NH}_{3}$ (in aqueous form) as one of the species and this uncharged aqueous $\mathrm{NH}_{3}$ being small in molecular size is highly likely to reverse diffuse through the FO membrane towards the feed further contributing to the RSF value. This is also probably the main reason why the $\mathrm{pH}$ of the FS was observed to increase above pH 9 when the FO was operated with DAP as DS. Once in the FS, $\mathrm{NH}_{3}$ is expected to slightly dissociate further to produce $\mathrm{NH}_{4}{ }^{+}$increasing $\mathrm{OH}^{-}$ions that give the $\mathrm{pH}$ rise.

The RSF of total $\mathrm{PO}_{4}$ ions, however, was observed to be higher for MAP compared to DAP, which is probably due to the differences in concentrations of $\mathrm{H}_{2} \mathrm{PO}_{4}{ }^{-}$species in their solutions. $\mathrm{H}_{2} \mathrm{PO}_{4}{ }^{-}$is one of the major phosphate species common to both MAP and 
DAP and is a monovalent anion. Thus, compared to other species which are mostly multivalent anions (e.g. $\mathrm{H}_{2} \mathrm{P}_{2} \mathrm{O}_{7}{ }^{2-}$ or $\mathrm{HPO}_{4}{ }^{2-}$ ), it is expected that $\mathrm{H}_{2} \mathrm{PO}_{4}{ }^{-}$will better diffuse through the membrane resulting in its accumulation on the feed solution. Table $\mathbf{S 2}$ shows that $1 \mathrm{M}$ MAP solution contains a much higher concentration of $\mathrm{H}_{2} \mathrm{PO}_{4}^{-}$(i.e. $0.953 \mathrm{M}$ ) than

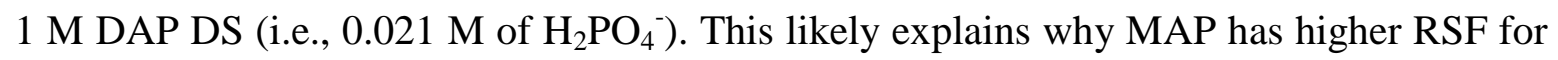
total $\mathrm{PO}_{4}$ ions compared to DAP as presented in Table S3.

Table 3. Water flux and reverse salt flux with different membrane orientation and draw solution concentration. Experiment conditions of FO experiments: DI water as feed solution; crossflow rate of $8.5 \mathrm{~cm} / \mathrm{s}$; temperature of $20 \pm 1^{\circ} \mathrm{C}$.

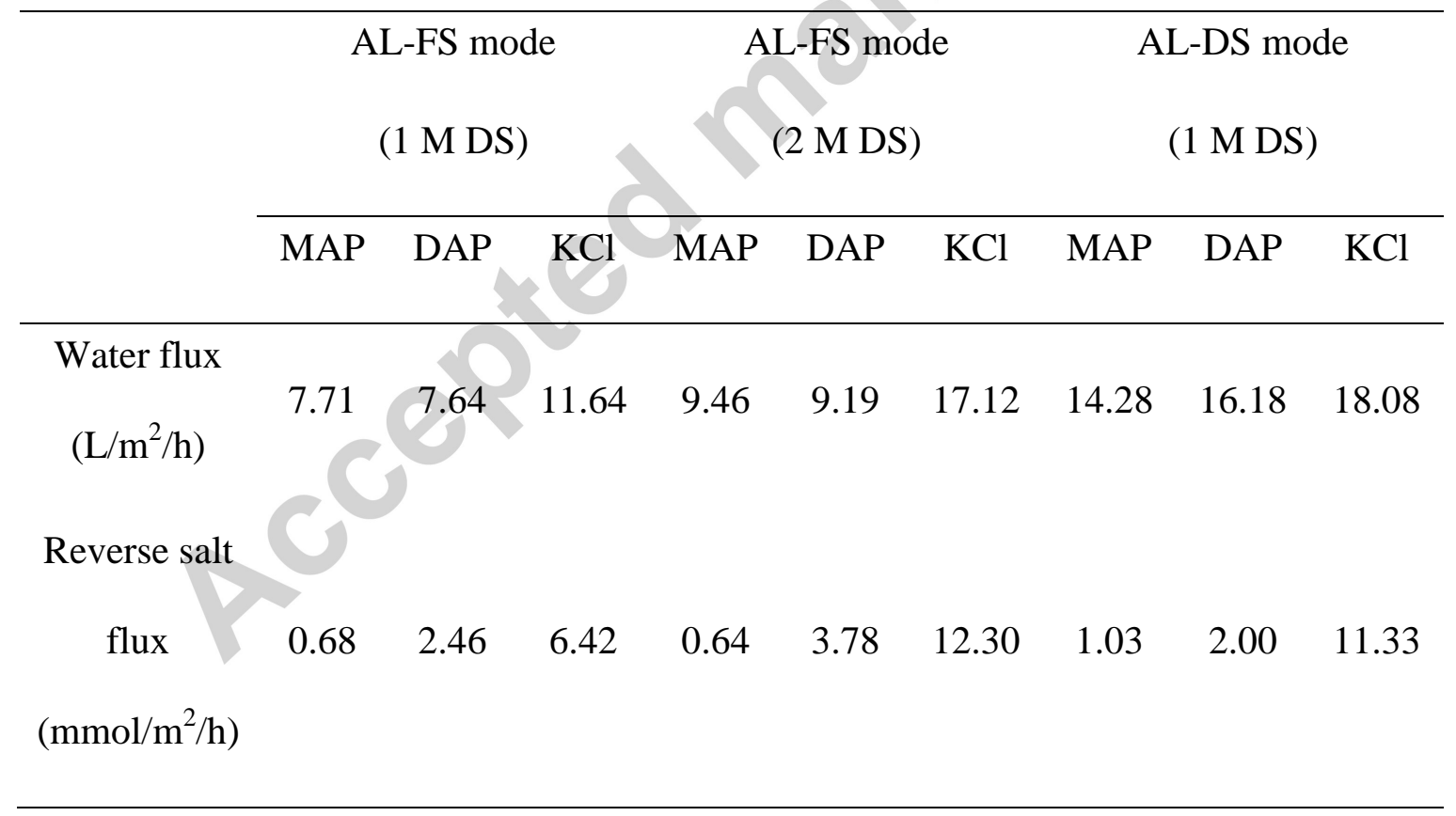




\subsubsection{Flux decline during AnMBR effluent treatment by FDFO}

FDFO experiments were conducted using AnMBR effluent as FS and the three fertilizers as DS with flux data are presented as normalized flux in Fig. 1. When FDFO experiments were first carried out at $1 \mathrm{M}$ DS under the AL-FS mode of membrane orientation, $\mathrm{KCl}\left(11.77 \mathrm{~L} / \mathrm{m}^{2} / \mathrm{h}\right)$ exhibited the highest initial water flux followed by MAP $\left(7.82 \mathrm{~L} / \mathrm{m}^{2} / \mathrm{h}\right)$ and DAP $\left(7.33 \mathrm{~L} / \mathrm{m}^{2} / \mathrm{h}\right)$, shown in Table 4, which is consistent with our earlier studies [25, 31]. As shown in Fig. 1a, all fertilizers tested did not show any flux decline during the $10 \mathrm{~h}$ of FO operation. Compared to the SEM image of the virgin membrane surface in Fig. 2a, the SEM images of the FO membrane surfaces after FO experiments in Fig. 2b and 2c with $\mathrm{MAP}$ and $\mathrm{KCl}$ appear very similar to the virgin membrane surface, suggesting that no significant fouling/scaling layer was formed on the membrane surface. However, results with DAP clearly show the presence of a partial scaling layer on the membrane surface (Fig. 2d), although no flux decline was also observed with this fertilizer (Fig. 1a).

Table 4. Initial water flux and average water flux with different membrane orientation and draw solution concentration. Experiment conditions of FO experiments: AnMBR effluent as feed solution; cross-flow rate of $8.5 \mathrm{~cm} / \mathrm{s}$; temperature of $20 \pm 1^{\circ} \mathrm{C}$.

\begin{tabular}{|c|c|c|c|c|c|c|c|c|}
\hline \multicolumn{3}{|c|}{ AL-FS mode } & \multicolumn{3}{|c|}{ AL-FS mode } & \multicolumn{3}{|c|}{ AL-DS mode } \\
\hline \multicolumn{3}{|c|}{ (1 M DS) } & \multicolumn{3}{|c|}{ (2 M DS) } & \multicolumn{3}{|c|}{ (1 M DS) } \\
\hline MAP & DAP & $\mathrm{KCl}$ & MAP & DAP & $\mathrm{KCl}$ & MAP & DAP & $\mathrm{KCl}$ \\
\hline
\end{tabular}




\begin{tabular}{llllllllll}
\hline Initial water & & & & & & & & & \\
flux & 7.82 & 7.33 & 11.77 & 9.4 & 9.16 & 17.62 & 13.25 & 12.84 & 15.64 \\
$\left(\mathrm{~L} / \mathrm{m}^{2} / \mathrm{h}\right)$ & & & & & & & & & \\
Average & & & & & & & & & \\
water flux & 7.58 & 7.35 & 11.20 & 9.23 & 8.72 & 16.32 & 10.48 & 5.10 & 9.44 \\
$\left(\mathrm{~L} / \mathrm{m}^{2} / \mathrm{h}\right)$ & & & & & & & & & \\
\end{tabular}
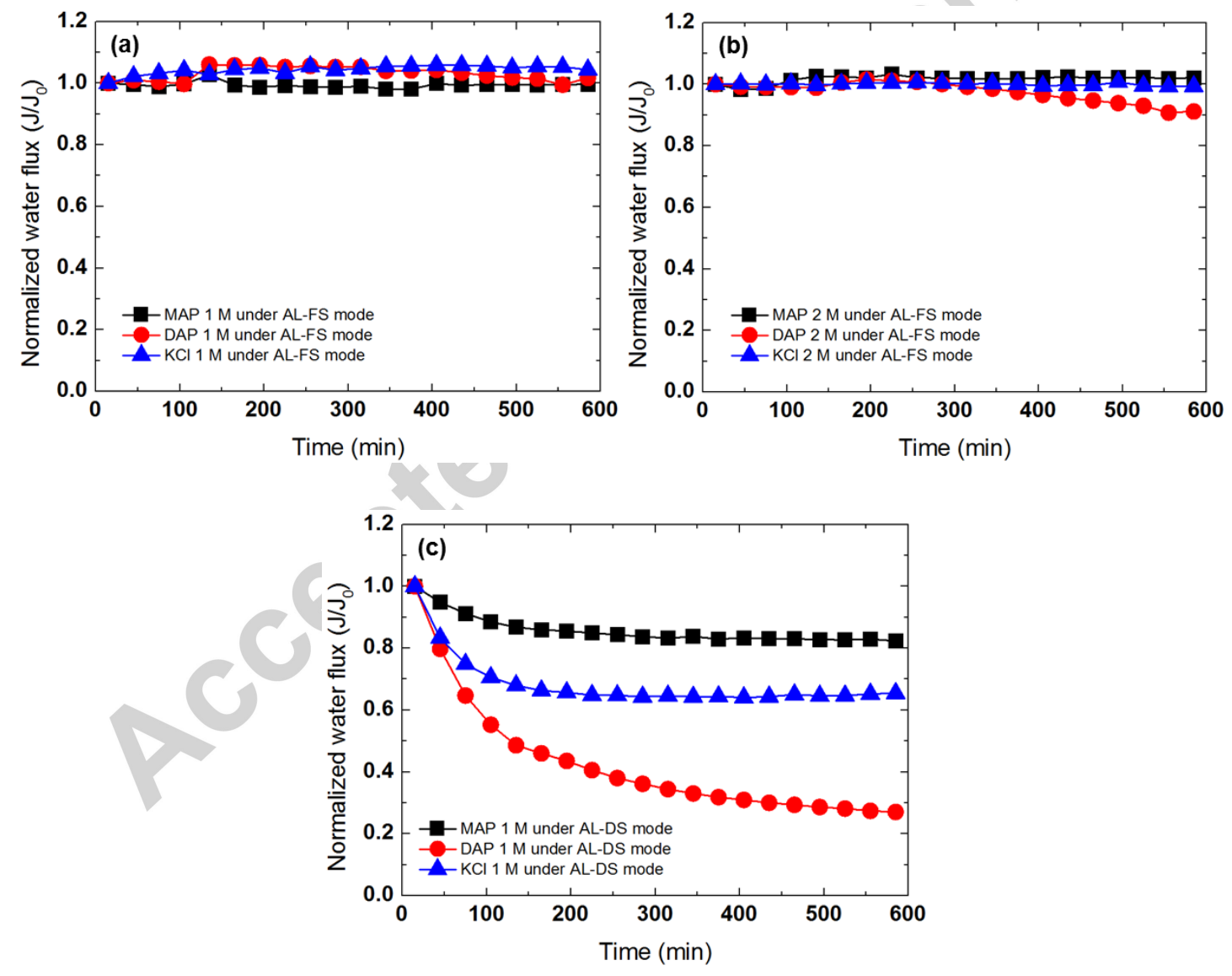

Fig. 1. Flux-decline curves obtained during FO experiments (a) under AL-FS mode at $1 \mathrm{M}$ draw solution, (b) under AL-FS mode at $2 \mathrm{M}$ draw solution, and (c) under AL-DS mode at 
$1 \mathrm{M}$ draw solution. Experimental conditions of all FO experiments: AnMBR effluent as feed solution; crossflow velocity of $8.5 \mathrm{~cm} / \mathrm{s}$; and temperature of $20 \pm 1{ }^{\circ} \mathrm{C}$.

A closer observation of membrane scales in Fig. 2d reveals that columnar jointing shaped crystals are formed on the membrane surface for DAP as DS. The deposition of scaling crystals on the membrane surface is in fact expected to increase the membrane resistance resulting in the water flux decline, however, such flux decline was not observed with DAP as DS. This could probably be explained by the membrane surface becoming more hydrophilic due to the presence of hydrophilic scales on the membrane surface. A slight decrease in the contact angle of the fouled membrane with DAP compared to virgin membrane was found, shown in Table S5. By improving its hydrophilicity, the membranes can exhibit higher water flux due to more favorable transport of water molecules through improved membrane wetting $[39,40]$. Hydrophilic scaling often occurs in the early stage of the scaling formation [41] which can enhance the transport of water molecules. Any slight flux decline from the increased membrane resistance due to partial scale formation on the membrane surface can thus be offset by the enhanced water flux from the improved hydrophilicity of the FO membrane surface. 


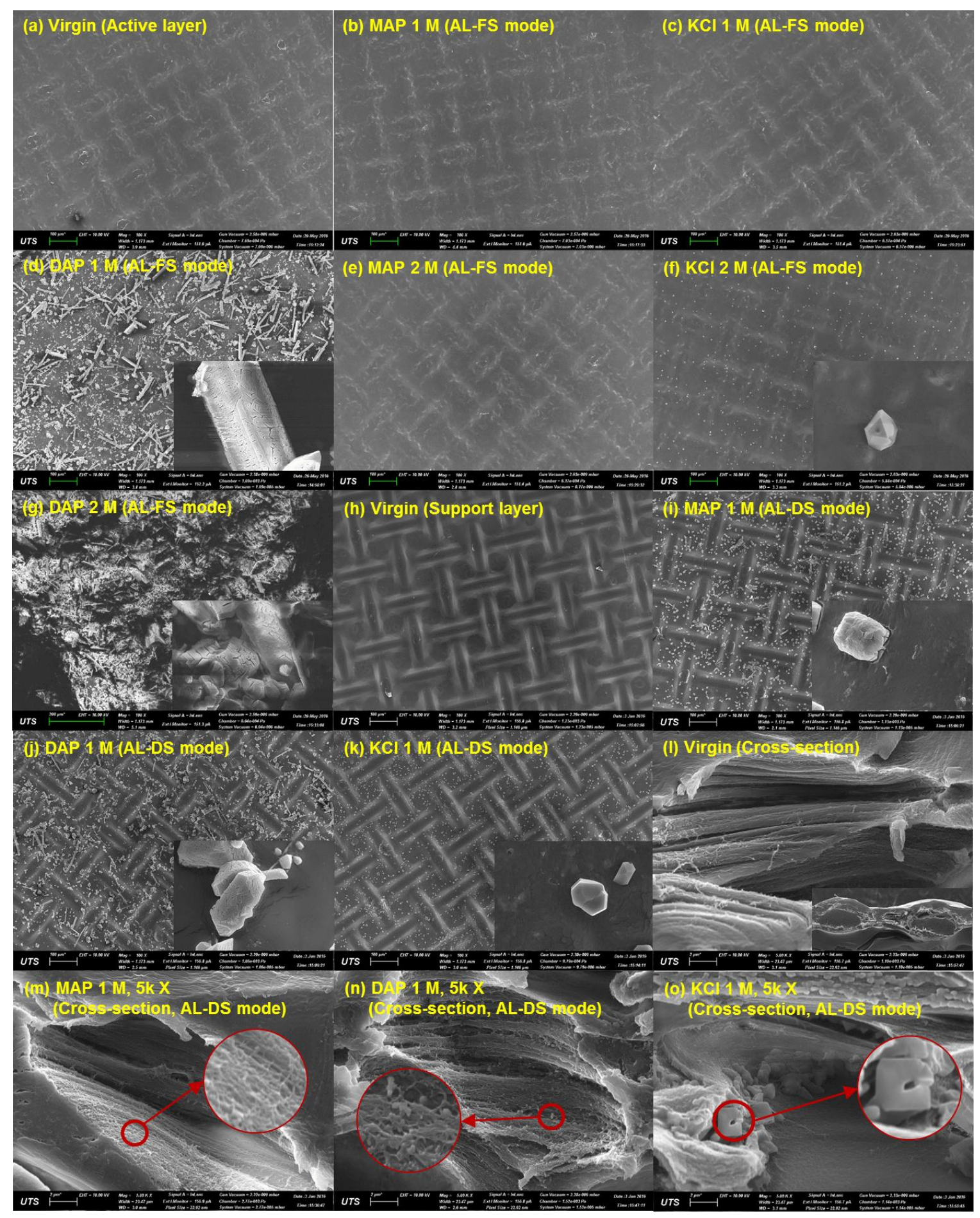

Fig. 2. SEM images of the active layer of (a) virgin membrane and fouled membrane under AL-FS mode at (b) MAP $1 \mathrm{M}$, (c) $\mathrm{KCl} 1 \mathrm{M}$, (d) DAP $1 \mathrm{M}$, (e) MAP $2 \mathrm{M}$, (f) KCl $2 \mathrm{M}$ and (g) DAP $2 \mathrm{M}$, the support layer of (h) virgin membrane and fouled membrane under AL-DS mode at (i) MAP $1 \mathrm{M}$, (j) DAP $1 \mathrm{M}$ and (k) $\mathrm{KCl} 1 \mathrm{M}$, and the cross-section under 5k $\mathrm{X}$ 
magnification of (l) virgin membrane and fouled membrane under AL-DS mode at (m) MAP $1 \mathrm{M}$, (n) DAP $1 \mathrm{M}$ and (o) $\mathrm{KCl} 1 \mathrm{M}$.

To investigate the effect of fertilizer concentration, FDFO experiments were conducted at $2 \mathrm{M}$ DS under the AL-FS mode. By doubling the DS concentrations, the initial water fluxes in all fertilizers were enhanced, shown in Table 4. Operating the FO process at higher flux is expected to not only to enhance dilutive ICP but also increase the permeation drag that could further result in fouling and more severe flux decline [27]. However, as shown in Fig. 1b, only DAP exhibited a slight flux decline while MAP and KCl DS did not show any noticeable flux decline. The membrane surface with MAP (Fig. 2e) does not appear to show occurrence of fouling, appearing similar to the virgin membrane surface (Fig. 2a). On the other hand, the membrane surface with $2 \mathrm{M} \mathrm{KCl}$ (Fig. 2f) was partially covered by small crystal-shaped scales, which are likely due to the $\mathrm{KCl}$ from the RSF that formed scales on the membrane surface as the RSF of $\mathrm{KCl}$ was quite significant compared to the other fertilizer DS (Table 3). However, it may be said that the scale formation due to $\mathrm{RSF}$ of $\mathrm{KCl}$ may be fairly low and not enough to cause significant flux decline during the $10 \mathrm{~h}$ of FO operation. In the case of DAP DS, about $10 \%$ decline in water flux is observed, probably because the membrane surface was fully covered by scales as shown in Fig. 2g. Interestingly, scaling fouling was mainly observed on the membrane surface while organic fouling would have slightly affected the FDFO performance even though AnMBR effluent is a complex mixture including organics, inorganics and contaminants. However, it can be expected that, if FDFO is operated in the long term, biofouling/organic fouling will significantly occur. 

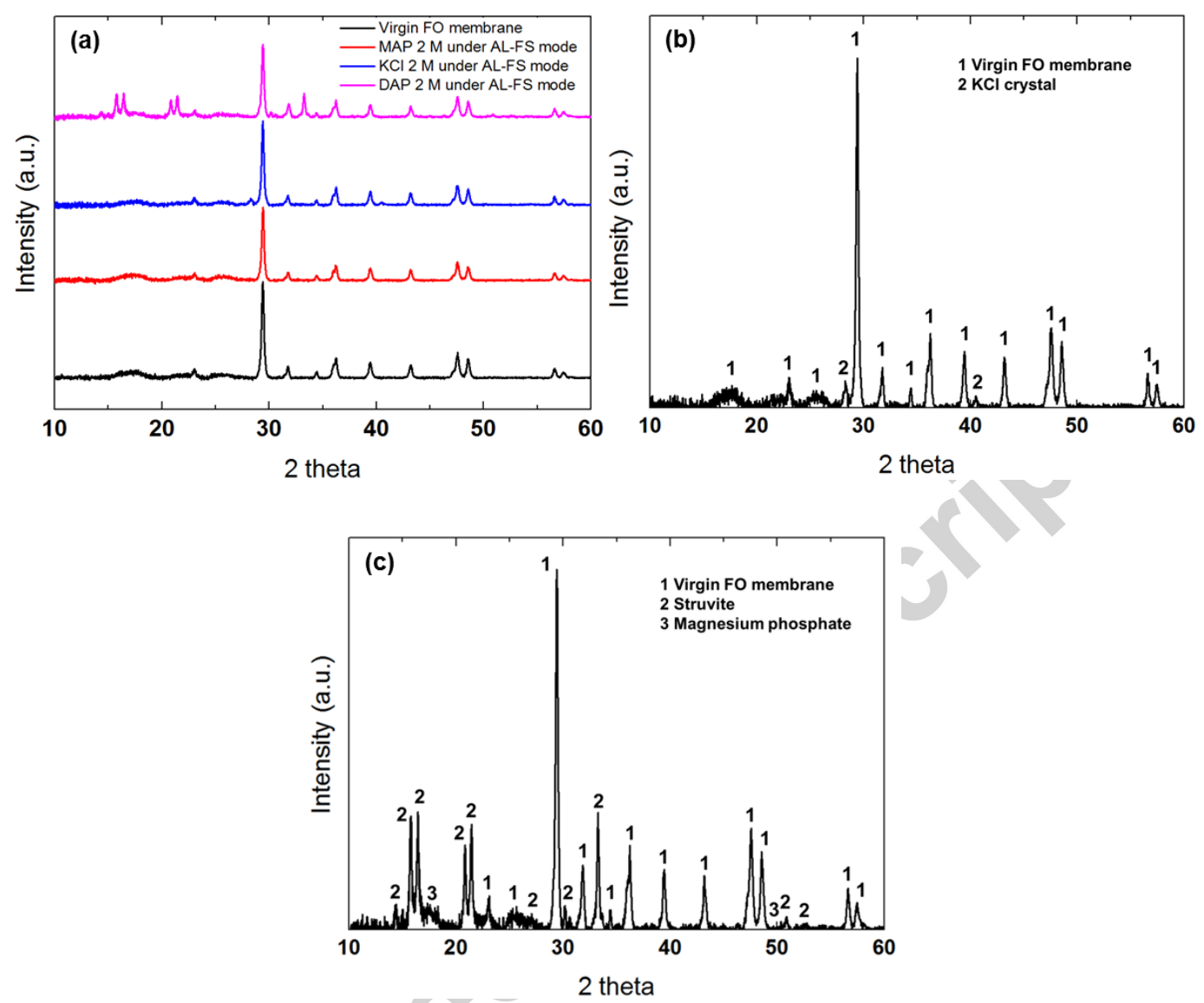

Fig. 3. XRD patterns of virgin and fouled membranes: (a) comparison of XRD peaks between virgin membrane and fouled membranes with three fertilizer draw solution, (b) comparison of XRD peaks between fouled membranes with $\mathrm{KCl} 2 \mathrm{M}$ and $\mathrm{KCl}$ crystal, and (c) comparison of XRD peaks between fouled membranes with DAP $2 \mathrm{M}$, magnesium phosphate, and magnesium ammonium phosphate (struvite). XRD analysis was performed on the active layer of FO membranes.

The scaling layer formed during FDFO experiments with DAP as DS was further studied by EDX analysis, which indicated the presence of magnesium and phosphorus 
elements (Fig. S2). Even though AnMBR effluent contains both $\mathrm{Mg}^{2+}$ and $\mathrm{PO}_{4}{ }^{3-}$ as listed in Table 1, only DAP caused magnesium and phosphate related scales. During FDFO experiments, $\mathrm{pH}$ of FS with DAP as DS slightly increased from 8 to 8.8 (Table S3) due to reverse diffusion of species found in the DAP DS which might have created a more ideal condition for phosphate precipitation with $\mathrm{Ca}^{2+}$ or $\mathrm{Mg}^{2+}$ cations [42] (e.g. magnesium phosphate $\left(\mathrm{Mg}\left(\mathrm{H}_{2} \mathrm{PO}_{4}\right)_{2}\right)$ or magnesium ammonium phosphate $\left(\mathrm{NH}_{4} \mathrm{MgPO}_{4} \cdot 6 \mathrm{H}_{2} \mathrm{O}\right)$ (struvite). Although FS was different, the results from this study are consistent with the results from our earlier study for brackish water desalination in FDFO [31].

To further identify the composition of the scaling layer, XRD analysis was carried out on the scaled membrane surface. Fig. 3a showed that the membrane with MAP has similar XRD peaks to the virgin membrane, indicating that no scaling layer was formed on the membrane surface. On the other hand, the XRD pattern for the FO membrane surfaces with $\mathrm{KCl}$ and DAP as DS exhibited different peaks than the virgin FO membrane peaks. $\mathrm{XRD}$ analysis confirmed that $\mathrm{KCl}$ crystals formed on the membrane surface in Fig. $2 \mathbf{f}$ with $\mathrm{KCl}$ as DS (Fig. 3b), and is likely from the reverse diffusion of $\mathrm{KCl}$. Since magnesium and phosphorous were found from EDX analysis, XRD peaks with DAP were first compared to reference peaks of magnesium phosphate (Fig. 3c), but the result was not conclusive. The XRD peaks agreed well when compared to the reference peaks of struvite (Fig. 3c), indicating that the scaling layer was primarily composed of struvite. This insoluble scaling formation can be caused by a combination of $\mathrm{pH}$ increase, the presence of $\mathrm{Mg}^{2+}$ in FS and supply of $\mathrm{NH}_{4}{ }^{+}$and $\mathrm{HPO}_{4}{ }^{2-}$ from DS as Eqn. (11) [42].

$$
\mathrm{HPO}_{4}{ }^{2-}+\mathrm{Mg}^{2+}+\mathrm{NH}_{4}^{+}+6 \mathrm{H}_{2} \mathrm{O} \rightarrow \mathrm{NH}_{4} \mathrm{MgPO}_{4} \cdot 6 \mathrm{H}_{2} \mathrm{O} \downarrow+\mathrm{H}^{+}
$$


For struvite formation, $\mathrm{HPO}_{4}{ }^{2-}$ ions should exist in solution, and they can only be formed under high $\mathrm{pH}$ (pKa 7.21). Speciation analysis in Table S2 also shows $0.947 \mathrm{M}$ of $\mathrm{HPO}_{4}{ }^{2-}$ ions formed in $1 \mathrm{M}$ DAP (negligible for MAP) which is also likely to reverse diffuse towards the feed. In addition, a pH increase of FS with DAP as shown in Table S4 provided a more favorable condition for struvite formation [42]. Moreover, higher RSF of the $\mathrm{NH}_{4}{ }^{+}$with DAP as DS also created more favorable conditions for struvite scaling.

To investigate the influence of membrane orientation on flux decline, the FDFO experiments were carried out under AL-DS mode at $1 \mathrm{M} \mathrm{DS}$, with flux results presented in Fig. 1c. Unlike the AL-FS mode of membrane orientation, the fouling and scaling are expected to occur inside the membrane support layer as the membrane support layer is in contact with the feed water. As expected, the initial water fluxes under the AL-DS mode were significantly higher (shown in Table 4) compared to those in AL-FS mode at the same concentration since ICP phenomenon became negligible under the AL-DS mode of membrane orientation [43]. However, the flux decline was observed to become more severe with all the fertilizer DS, with DAP showing the highest flux decline followed by $\mathrm{KCl}$ and MAP. Despite DAP and MAP having similar initial water flux, DAP showed much higher flux decline compared to MAP. Comparing SEM images in Fig. $\mathbf{2 i}$ and $\mathbf{2 j}$, it appears that the membrane surface of the support layer side with DAP is covered by a slightly higher amount of scales compared to MAP. However, the surface scaling results alone do not appear to be sufficient to explain the significant flux decline observed with DAP. Therefore, a cross-section of fouled FO membranes was also analyzed to have further insight into scaling issues inside the membrane inner structure. Fig. 2n shows the presence of a large 
amount of small scales inside the support layer with DAP, while the support layer with MAP (Fig. 2m) was very similar to the virgin membrane (Fig. 2l). Based on these results, it can be speculated that phosphate precipitates, such as struvite scales, may also be formed within the pores of the support layer due to the reverse diffusion of $\mathrm{NH}_{4}{ }^{+}$and $\mathrm{HPO}_{4}{ }^{2-}$ from DAP and the presence of $\mathrm{Mg}^{2+}$ in the feed solution thereby contributing to the severe flux decline.

$\mathrm{KCl}$ showed higher flux decline than MAP, which may be explained by its higher initial water flux that results in a higher permeation drag force and higher concentrative concentration polarization which enhances the deposition and accumulation of foulants on the membrane support layer. Although $\mathrm{KCl}$ (Fig. 2k) shows a slightly less scale deposition on the membrane support surface compared to with MAP (Fig. 2i), this is also a possible reason why $\mathrm{KCl}$ had a higher flux decline compared to MAP. Unlike the AL-FS mode of FO operation, the foulant deposition occurs inside the support layer where the hydrodynamic crossflow shear is not effective in removing the foulant from the membrane resulting in a higher flux decline. In addition, Fig. 20 appears to show some form of inorganic scaling crystals present inside the membrane support layer with $\mathrm{KCl}$ as DS, however, it is not clear whether these crystals were actually insoluble precipitates that contributed to flux decline or $\mathrm{KCl}$ from the $\mathrm{DS}$ itself not fully removed before taking the membrane samples for SEM imaging. $\mathrm{K}_{2} \mathrm{SO}_{4}$ being much lower in solubility, is a potential candidate that can cause scaling with $\mathrm{KCl}$ DS when operated at a higher water flux, and further aggravated by higher RSF of the $\mathrm{KCl}$ that can slightly enhance concentrative ICP on the support layer side of the FO membrane. 


\subsubsection{Influence of physical cleaning on flux recovery}

The effectiveness of physical (hydraulic) cleaning on the FO water flux recovery after AnMBR effluent treatment is presented in Fig. 4a. It was observed that under the ALFS mode, FO membrane water fluxes were fully recovered for all the fertilizer DS tested, irrespective of DS concentrations used since high crossflow could induce high shear force (i.e., Re increased from 491 to 1474 close to turbulent flow). This further supports findings

(Section 3.1.2) that the membrane fouling layer formed on the active layer could be readily removed by physical hydraulic cleaning. It is interesting to note that the water flux was also fully recovered for FO membranes subjected to scaling when operated with $2 \mathrm{M}$ DAP as DS. In order to confirm whether the fouling layer was completely removed, SEM analysis was carried out using the fouled FO membranes with DAP since membrane fouling was the severest with this DS. Fig. S3a and S3b show that the scaling layer was almost fully removed by physical washing. Results of contact angle analysis were also consistent with the SEM analysis. After physical cleaning, contact angles of cleaned FO membrane surfaces with all fertilizers under AL-FS mode were almost restored, shown in Table S5.

The water fluxes could not be fully recovered after physical cleaning for the FO membranes operated under the AL-DS mode, where MAP and $\mathrm{KCl}$ showed $>90 \%$ recovery while DAP was only about $25 \%$. However, it is interesting to note that physical cleaning was effective to restore the water flux by more than $90 \%$ for $\mathrm{KCl}$ and MAP DS despite the fact that the fouling is expected to occur inside the support layer side of the FO membrane which is unaffected by the crossflow velocity shear. This may be related to the structure of 
the FO membrane where it is apparent that CTA FO membranes do not have a distinct support layer and active layer unlike the TFC FO membranes [44]. The woven backing fabric generally considered as a support layer for the CTA FO membrane is in fact embedded within the cellulose triacetate layer which is the active rejection layer, thereby giving a FO membrane without a distinct porous support layer. This is also the main reason why CTA FO membranes do not have a significant FO pure water flux difference when operated under AL-FS or AL-DS modes of membrane orientations, unlike TFC FO membranes where pure water fluxes under the AL-DS mode is significantly higher [44, 45]. Therefore, it is apparent that physical cleaning was quite effective in removing the foulant deposited on the support layer side of the CTA FO membrane although it was not as effective in cleaning the active layer side of the FO membrane.

The poor flux recovery rate of FO membranes operated with DAP DS shows that hydraulic cleaning was not effective in removing the membrane foulant and scales formed on the support layer (Fig. S3c) as well as on the surface (Fig. S3e). While it is expected that some of the foulants and scales deposited on the surface of the support layer are removed by physical cleaning, those formed inside the support layer are not influenced by the crossflow. Besides, struvite is only sparingly soluble in DI water under neutral and alkaline conditions thereby rendering the physical washing ineffective for FO membrane operated with DAP DS.

In order to enhance the cleaning efficiency for FO membranes operated under the AL-DS mode, osmotic backwashing was investigated for fouled FO membranes using DI water on the active layer and $1 \mathrm{M} \mathrm{NaCl}$ on the support layer side at the same crossflow 
velocity (i.e., $8.5 \mathrm{~cm} / \mathrm{s}$ for $30 \mathrm{mins}$ ). Fig. $\mathbf{4 b}$ shows that water flux recovery after osmotic backwashing was not significantly better than physical cleaning for $\mathrm{MAP}$ and $\mathrm{KCl}$ and hence still did not result in $100 \%$ flux recovery. Interestingly, the FO water flux with DAP was restored to about $80 \%$, indicating that osmotic backwashing was effective in removing the foulants and scales deposited inside the FO support layer, shown in Fig. S3f. During osmotic backwashing, the water flux is reversed and the permeation drag force occurs from the active layer side to the support layer side of the FO membranes. This mode of cleaning is expected to partially remove the foulants and scales present in the pores and remove them out of the membrane support layer. It should be noted that the use of $\mathrm{NaCl}$ salt solution as a cleaning agent might induce other phenomena such as changing the structure of the cross-linked gel layer on the membrane surface by an ion exchange reaction which can break up calcium-foulant bonds when the fouling layer is exposed to the salt solution [46-48]. Similarly, DS with $1 \mathrm{M} \mathrm{NaCl}$ might affect struvite dissolution through an ion exchange reaction. As a result, osmotic backwashing was a more effective cleaning method than physical washing to remoye the scales present within the support layer.
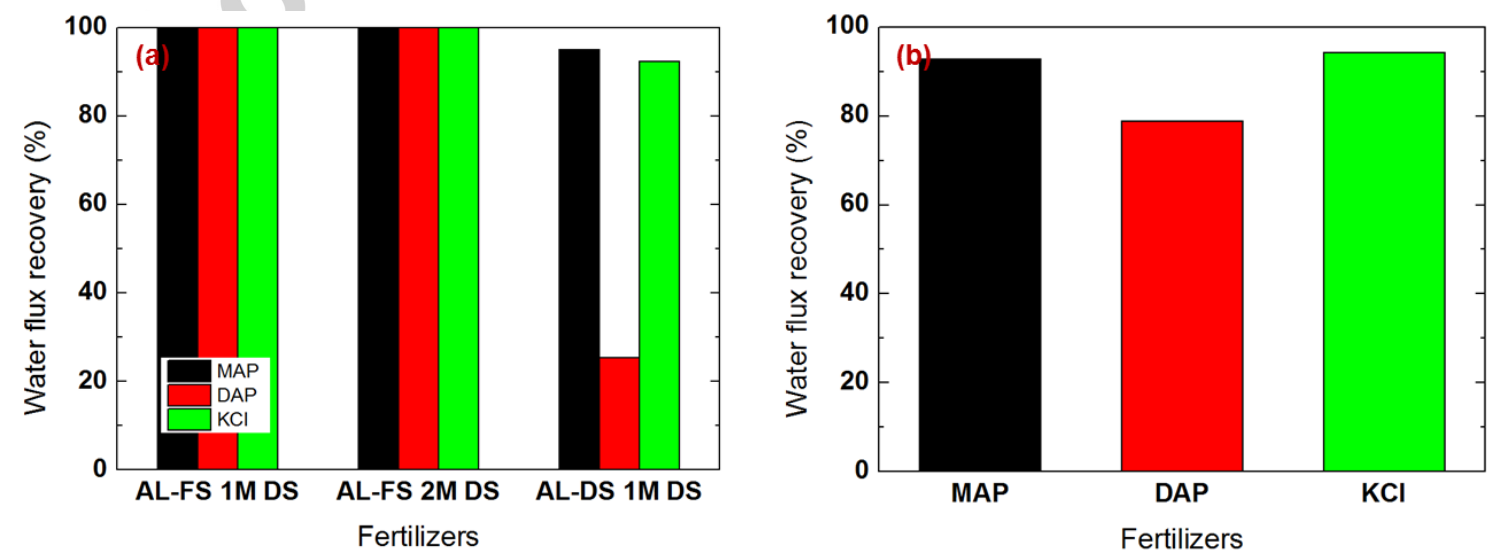
Fig. 4. Water flux recovery after (a) physical washing and (b) osmotic backwashing. Experimental conditions for physical washing: DI water as feed and draw solutions; crossflow velocity of $25.5 \mathrm{~cm} / \mathrm{s}$; cleaning duration of $30 \mathrm{~min}$; and temperature of $20 \pm 1{ }^{\circ} \mathrm{C}$. Experimental conditions for osmotic backwashing: $1 \mathrm{M} \mathrm{NaCl}$ as feed solution; DI water as draw solution; crossflow velocity of $8.5 \mathrm{~cm} / \mathrm{s}$; cleaning duration of $30 \mathrm{~min}$; and temperature of $20 \pm 1{ }^{\circ} \mathrm{C}$.

\subsection{Influence of fertilizer DS properties on OMPs transport}

During FDFO operations using AnMBR effluent treatment, OMPs transport behavior was also studied by measuring the OMPs forward flux, presented in Fig 5. It is clear from Fig. 5(a) that the highest OMPs flux was observed with $\mathrm{KCl}$ as DS, except for Atenolol where the OMPs fluxes were fairly similar with all the three fertilizer DS, while the OMPs fluxes for MAP and DAP were comparable. For the three OMPs tested, the highest flux was observed for Caffeine, closely followed by Atrazine, and Atenolol showing the lowest flux with all the fertilizer DS. Since a higher flux relates to a lower OMPs rejection rate by the FO membrane, a lower OMPs flux is desirable for FDFO. The specific OMPs permeate concentrations and their rejection rates by the FO membrane are presented in Table 5.

The higher OMPs flux for $\mathrm{KCl}$ compared to MAP and DAP may be explained by the higher average FO water flux of $\mathrm{KCl}\left(11.2 \mathrm{~L} / \mathrm{m}^{2} / \mathrm{h}\right.$ in Table 4) compared to MAP (7.58 $\left.\mathrm{L} / \mathrm{m}^{2} / \mathrm{h}\right)$ and DAP $\left(7.35 \mathrm{~L} / \mathrm{m}^{2} / \mathrm{h}\right)$ DS. The average water flux in this particular case was calculated by dividing the total volume of FO permeate that crossed the FO membrane from the feed to the DS tank, divided by the effective membrane area and the duration of the FO operation in the batch process. In any salt-rejecting membrane processes, external 
concentration polarization (ECP) plays an important role in determining the forward salt flux and rejection rates [49]. At higher water fluxes, salt concentration at the membrane surface increases due to enhanced concentrative ECP (under the AL-FS mode) and thus increases the forward salt flux through the membrane. MAP and DAP have comparable average water fluxes under the AL-FS mode at $1 \mathrm{M}$ concentration (Table 4) which contributes to almost similar concentrative ECP and hence resulting in comparable OMPs fluxes. Generally, the rejection rate in FO is higher than that in the RO process, where previous studies have linked this to a probable hindrance effect of RSF on the forward transport [16]. Based on this assumption, $\mathrm{KCl}$ with the highest $\mathrm{RSF}$ is expected to have lower OMPs forward flux compared to MAP and DAP that have significantly lower RSF. Although the water fluxes of the MAP and DAP fertilizer DS are similar (Table 4), the RSF of DAP is significantly higher than MAP while their OMPs forward fluxes are observed to be similar. These results suggest that the effect of ECP by permeation drag force is more significant than the hindrance effect by RSF, which is consistent with a previous study [34]. For instance, if certain DS has higher water flux as well as higher RSF than others, rejection rates can be seriously reduced even though high RSF has a potential impact on enhancing the rejection propensity. 

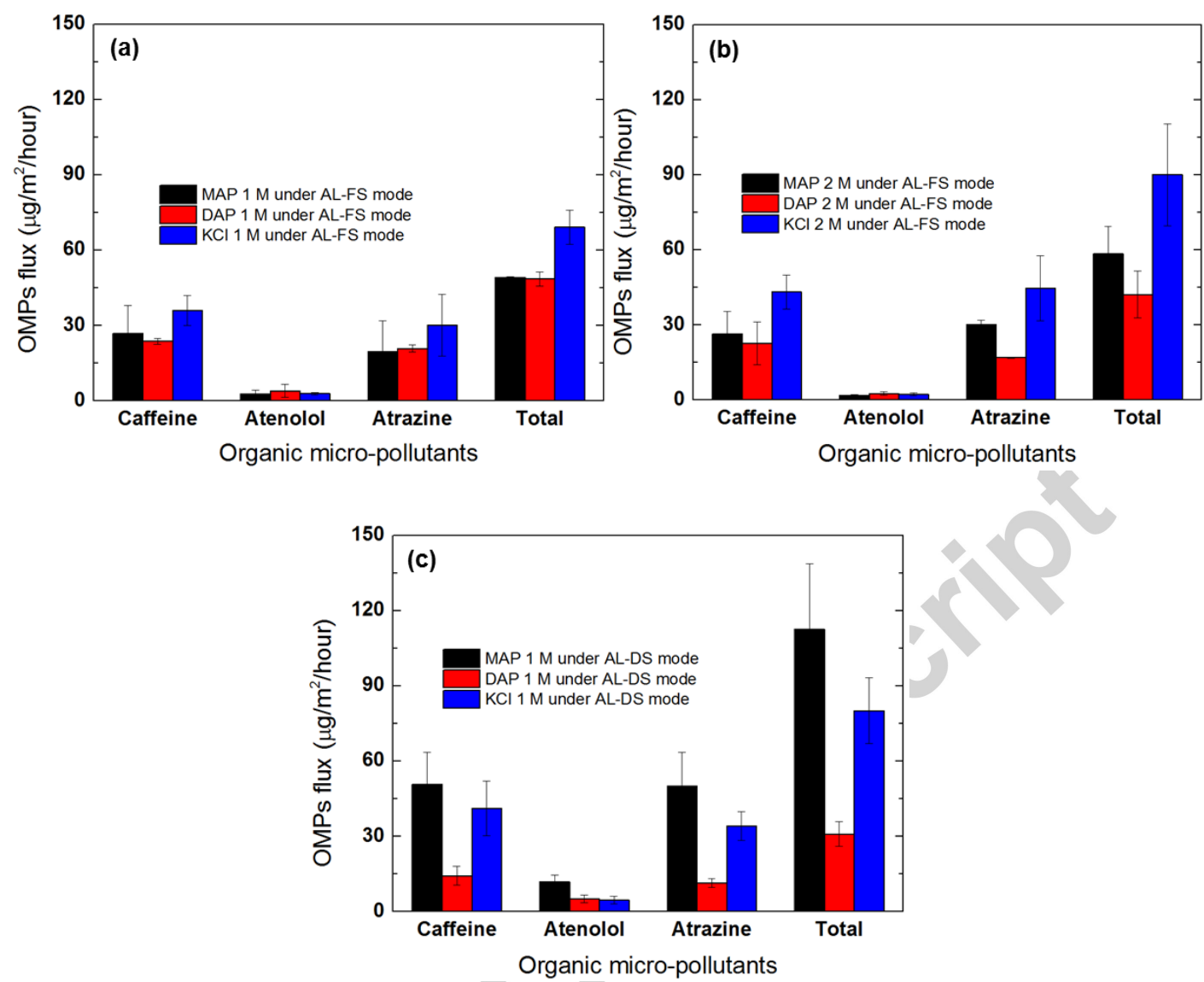

Fig. 5. Comparison of OMPs forward flux in FDFO between MAP, DAP and KCl: (a) under AL-FS mode at $1 \mathrm{M}$ draw solution, (b) under AL-FS mode at $2 \mathrm{M}$ draw solution, and (c) under AL-DS mode at $1 \mathrm{M}$ draw solution. The error bars represent the standard deviation from duplicate measurements. Experimental conditions for OMPs transport behaviors: AnMBR effluent with $10 \mu \mathrm{g} / \mathrm{L}$ OMPs as feed solution; crossflow velocity of 8.5 $\mathrm{cm} / \mathrm{s} ; 10 \mathrm{~h}$ operation; and temperature of $20 \pm 1{ }^{\circ} \mathrm{C}$. 
Table 5. Permeate OMPs concentration and OMPs rejection with different membrane orientation and draw solution concentration. Experimental conditions for OMPs transport behaviors: AnMBR effluent with $10 \mu \mathrm{g} / \mathrm{L}$ OMPs as feed solution; crossflow velocity of 8.5 $\mathrm{cm} / \mathrm{s} ; 10 \mathrm{~h}$ operation; and temperature of $20 \pm 1{ }^{\circ} \mathrm{C}$.

\begin{tabular}{|c|c|c|c|c|c|c|c|c|c|c|}
\hline & \multirow{2}{*}{\multicolumn{3}{|c|}{$\begin{array}{l}\text { AL-FS mode } \\
\text { (1 M DS) }\end{array}$}} & \multirow{2}{*}{\multicolumn{3}{|c|}{$\begin{array}{l}\text { AL-FS mode } \\
\text { (2 M DS) }\end{array}$}} & \multirow{2}{*}{\multicolumn{3}{|c|}{$\begin{array}{c}\text { AL-DS mode } \\
\text { (1 M DS) }\end{array}$}} \\
\hline & & & & & & & & & & \\
\hline & & MAP & DAP & $\mathrm{KCl}$ & MAP & DAP & $\mathrm{KCl}$ & MAP & DAP & $\mathrm{KCl}$ \\
\hline \multirow{4}{*}{ مَ } & Caffeine & 0.47 & 0.41 & 0.59 & 0.45 & 0.39 & 0.65 & 0.94 & 0.25 & 0.82 \\
\hline & Atenolol & 0.05 & 0.07 & 0.05 & 0.03 & 0.04 & 0.03 & 0.23 & 0.08 & 0.09 \\
\hline & Atrazine & 0.34 & 0.36 & 0.49 & 0.51 & 0.29 & 0.67 & 0.78 & 0.20 & 0.59 \\
\hline & Total & 0.85 & 0.85 & 1.13 & 0.99 & 0.72 & 1.36 & 1.94 & 0.53 & 1.50 \\
\hline \multirow{4}{*}{ 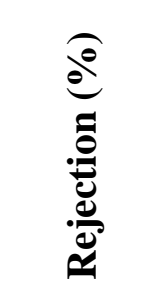 } & Caffeine & 95.3 & 95.9 & 94.1 & 95.5 & 96.1 & 93.5 & 90.6 & 97.5 & 91.8 \\
\hline & Atenolol & 99.5 & 99.3 & 99.5 & 99.7 & 99.6 & 99.7 & 97.7 & 99.2 & 99.1 \\
\hline & Atrazine & 96.6 & 96.4 & 95.1 & 94.9 & 97.1 & 93.3 & 92.2 & 98.0 & 94.1 \\
\hline & Total & 97.2 & 97.2 & 96.2 & 96.7 & 97.6 & 95.5 & 93.5 & 98.2 & 95.0 \\
\hline
\end{tabular}

The OMPs transport behavior is also significantly affected by OMPs properties (i.e., molecular weight, surface charge, and surface hydrophobicity). In both RO and FO, OMPs molecular weights have a significant impact on OMPs transport behavior by the steric hindrance that depends on the mean effective pore size of the membrane used [16, 50]. In addition, the surface charges of the OMPs also significantly affect the OMPs transport behavior by electric repulsion with membranes that contain surface charges [35]. 
Furthermore, rejection of OMPs with hydrophobic properties can be enhanced by hydrophobic-hydrophilic repulsion when using hydrophilic membranes [51].

In this study, Atenolol showed the lowest OMPs flux and therefore the highest rejection rates (> 99\%) followed by Atrazine (95-96.5\%) and Caffeine (94-96\%), giving a total OMPs rejection rate between 96-97\% for the three fertilizer DS. The highest rejection rate for Atenolol is likely because it has the largest molecular weight compared to the other two OMPs. The forward OMPs flux is a function of the molecular weight (shown in Fig. 6) where the linear decrease in the rejection rate observed with the increase in the molecular weight is consistent with other studies $[14,15,50]$. High molecular weight OMPs can be more easily rejected by FO membranes through steric hindrance [50]. In addition to molecular weight, the surface charge of OMPs may also have an influence on OMPs transport behavior. Table 2 presents that atenolol is positively charged while atrazine and caffeine are neutral. Thus, atenolol has much higher hydrated molecular dimension as well as higher molecular weight itself compared to uncharged OMPs (i.e., atrazine and caffeine). Since CTA membrane is relatively uncharged under the conditions tested in this study, these results indicate that the steric hindrance by the FO membrane is likely the dominant rejection mechanisms affecting OMPs transport behavior. 


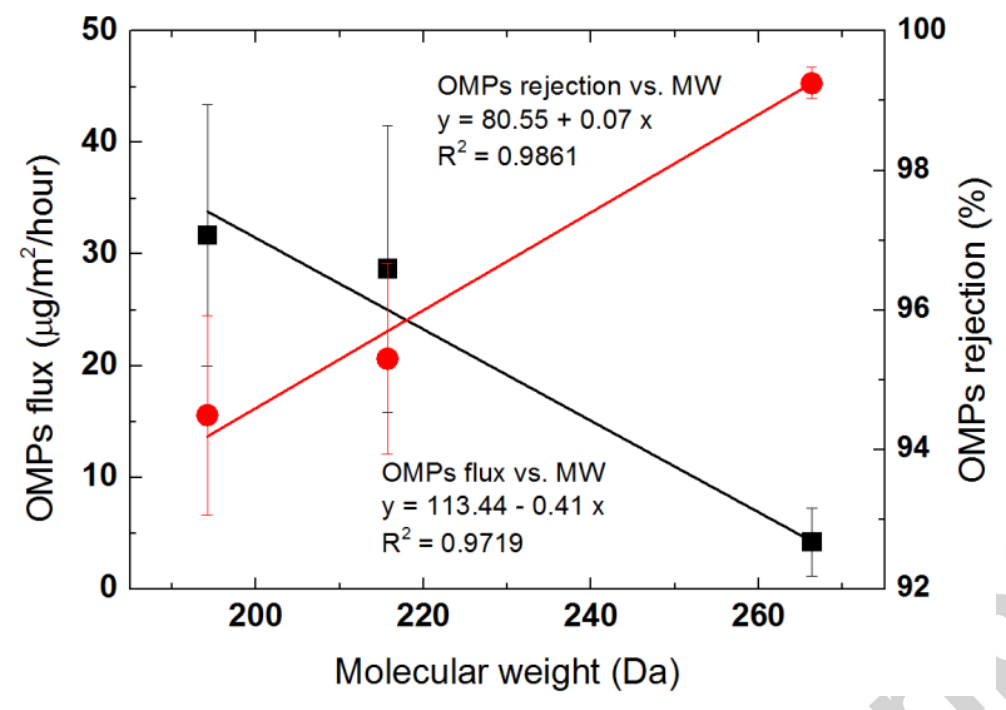

Fig. 6. Relationship of molecular weights of OMPs with OMPs flux and rejection, respectively.

Table 5 shows the OMPs concentrations measured in the FO permeate. These results indicate that the individual OMP concentrations in the permeate is consistently lower than $1 \mu \mathrm{g} / \mathrm{L}$ for all three fertilizers as DS, under conditions applied in this study. This concentration is well within the permissible limit for irrigation where the maximum allowable concentration is $1 \mu \mathrm{g} / \mathrm{L}$ [8]. However, we only considered a mixture of three OMPs in the AnMBR effluent which is probably less than what is present in real AnMBR effluent. Therefore, more investigation would be required to conclude the feasibility of AnMBR-FDFO for direct irrigation application.

\subsection{Influence of DS concentration on OMPs transport}

In order to investigate the influence of fertilizer DS concentration on OMPs transport, FDFO OMPs flux data for 1 M (Fig. 5a) DS concentration is compared with the 
2 M (Fig. 5b) DS concentrations under the AL-FS mode. The total OMPs forward flux for MAP and $\mathrm{KCl}$ increased slightly at higher DS concentration (2 M), which is likely due to the enhanced concentrative ECP as their average water fluxes at $2 \mathrm{M}$ is higher than $1 \mathrm{M}$ DS concentrations. However, the same trend did not apply to DAP as its total OMPs forward flux rather decreased at $2 \mathrm{M}$ compared to $1 \mathrm{M}$ although the average water flux increased from $7.35 \mathrm{~L} / \mathrm{m}^{2} / \mathrm{h}$ to $8.72 \mathrm{~L} / \mathrm{m}^{2} / \mathrm{h}$ (Table 4). This unexpected behavior is likely due to membrane fouling, where about 10\% flux decline was observed with $2 \mathrm{M}$ DAP as DS and not observed with $1 \mathrm{M}$ DAP as DS. When the fouling layer is formed on the membrane surface, it alters the surface properties and hence the solute rejection properties depending on the severity and type of fouling layer formed [52, 53]. In a colloidal fouling, for example, a porous fouling layer induces cake-enhanced concentration polarization (CECP) and accelerates feed salt permeability [53]. In organic fouling, however, a non-porous and dense fouling layer leads to cake-reduced concentration polarization (CRCP) which reduces salt permeability and hence improves salt rejection [52]. With 2 M DAP as DS, the nonporous, thick and dense fouling layer was formed (shown in Fig. 2g) where both scaling and organic fouling could have likely caused a CRCP effect resulting in lower OMPs forward flux. In terms of OMPs rejection rates in Table 5, increasing DS concentration under AL-FS mode lowers the OMPs rejection rates for all the fertilizer DS due to enhanced water flux that enhances concentrative ECP. 


\subsection{Influence of FO membrane orientation on OMPs transport}

OMPs forward flux with MAP as DS was significantly enhanced when operated under the AL-DS mode of membrane orientation (Fig 5c), compared to the AL-FS mode (Fig 5a). Similarly, OMPs forward flux increased with $\mathrm{KCl}$ as DS although the increase was not as high as with MAP. Interestingly, the OMP flux significantly decreased with DAP as DS. These phenomena may be likely due to the concentrative ICP effect and fouling occurring inside the membrane support layer.

The water flux for $1 \mathrm{M}$ MAP under the AL-DS mode was $10.5 \mathrm{~L} / \mathrm{m}^{2} / \mathrm{h}$, higher than under the AL-FS mode $\left(7.6 \mathrm{~L} / \mathrm{m}^{2} / \mathrm{h}\right)$. This higher water flux enhances the concentrative ICP thereby likely increasing the OMPs concentration at the membrane and hence its flux through the FO membrane [35]. Under the AL-DS mode, the water fluxes are generally higher due to higher effective concentration difference across the membrane active layer [43]. As per earlier observations (Fig 4a), a slight membrane fouling had occurred with 1 M MAP under the AL-DS mode of membrane orientation, where the water flux was not fully recovered by physical cleaning. As this fouling likely occurred inside the support layer side of the FO membrane, the deposited foulant or cake layer could reduce backdiffusion of the OMPs thereby likely contributing to enhanced OMPs flux.

The average water flux for $\mathrm{KCl}$ under the AL-DS mode $\left(9.44 \mathrm{~L} / \mathrm{m}^{2} / \mathrm{h}\right)$ was lower compared to the AL-FS mode $\left(11.2 \mathrm{~L} / \mathrm{m}^{2} / \mathrm{h}\right)$, however, the OMPs forward flux increased under the AL-DS mode. This phenomenon can be elucidated due to the combined effects of enhanced concentrative ICP and fouling inside the FO membrane support layer. Under the AL-DS mode of membrane orientation, foulants can be easily deposited inside the 
membrane support layer due to high initial permeation drag force since $\mathrm{KCl}$ had a much higher initial water flux $\left(15.6 \mathrm{~L} / \mathrm{m}^{2} / \mathrm{h}\right.$ in Table 4) although the average water flux decreased to around $9.4 \mathrm{~L} / \mathrm{m}^{2} / \mathrm{h}$ during the period of operation. This increased fouling inside FO membrane support layer not only lowers water flux but also can potentially prevent backdiffusion of OMPs to the feed side, similar to the observation with MAP, thereby increasing its flux through the FO membrane. This phenomenon as outlined is schematically presented in Fig. 7a.

The decrease in the OMPs flux with DAP under the AL-DS mode of membrane orientation is likely due to the combination of a much reduced average water flux compared to under the AL-FS mode. This reduction in average water flux might induce the decrease in OMPs flux by mitigating concentrative ICP. Moreover, the severe flux decline observed with DAP under the AL-DS mode is probably due to both struvite scaling and organic fouling, which may reduce the membrane porosity and pore size thus likely reducing the mass transfer of the OMPs and increasing the OMPs solute rejection by size exclusion [54] and hence decreasing the OMPs flux as explained in Fig. $\mathbf{7 b}$. 
(a) MAP and KCI DS under AL-DS mode

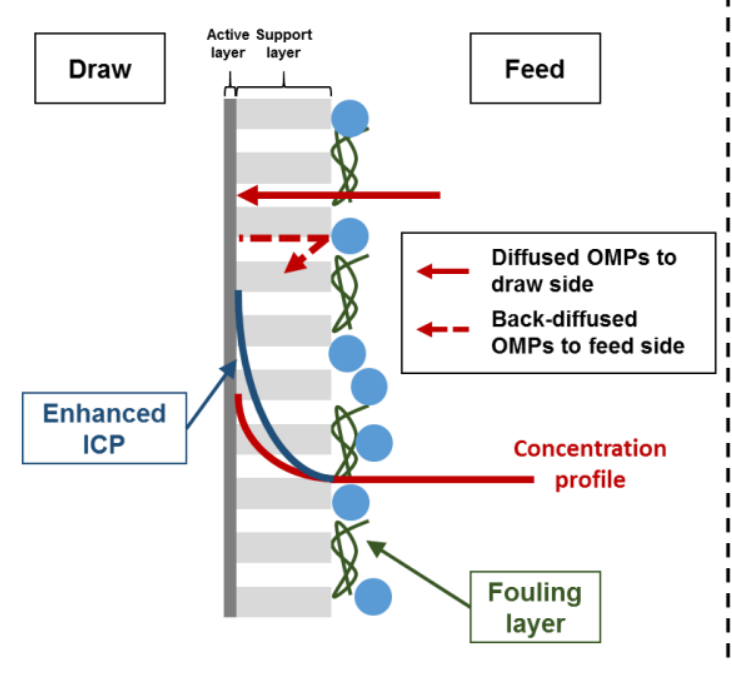

(b) DAP DS under AL-DS mode

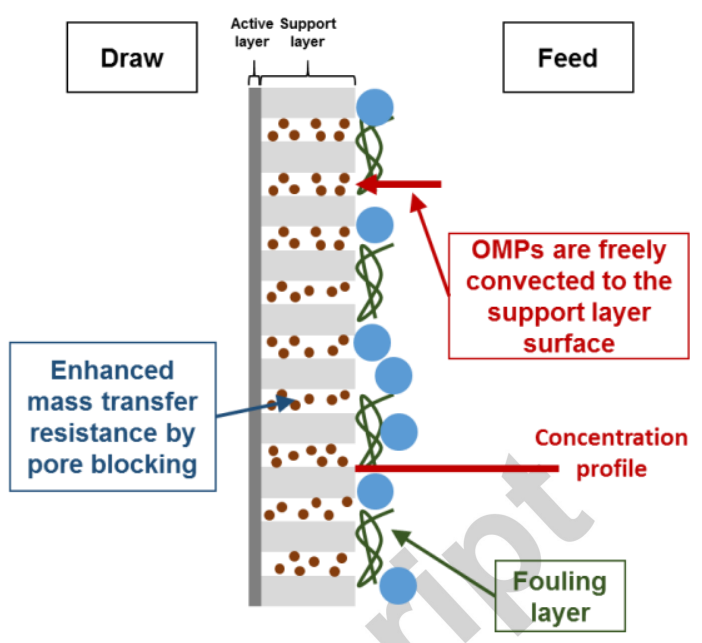

Fig. 7. Schematic description of OMPs transport mechanisms under AL-DS mode: (a) MAP and $\mathrm{KCl}$, and (b) DAP.

\section{Conclusions}

In this study, fouling behavior in FDFO was systematically investigated using three different fertilizer DS and included OMPs transport behavior during AnMBR effluent treatment. The primary findings from this study are summarized as follows:

- Under the AL-FS mode of membrane orientation, water flux with FDFO did not decline significantly due to the hydrophilicity of the scaling layer, even though severe scaling occurred when DAP fertilizer was used as DS.

- Under the AL-DS mode, DAP fertilizer DS showed the highest flux decline followed by $\mathrm{KCl}$ and $\mathrm{MAP}$, where scaling was observed within the support layer pores when DAP fertilizer was used as DS. 
- Physical/hydraulic cleaning successfully recovered water flux for the FO membranes operated under the AL-FS mode of membrane orientation. However, for the membranes operated under AL-DS mode, the flux was not fully recovered as the fouling and scaling occurred inside the support layer. Osmotic backwashing significantly enhanced the cleaning efficiency and flux recovery for FO membranes operated under the AL-DS mode.

- During the AnMBR effluent treatment by FDFO, DAP fertilizer DS exhibited the lowest OMPs forward flux (or the highest OMPs removal of up to 99\%) compared to MAP and $\mathrm{KCl}$ fertilizers as DS. The higher OMPs flux resulted in higher water flux that enhanced concentrative ECP on the membrane active surface and no significant influence of reverse solute flux was observed on the OMPs flux.

Findings from this study have significant implications for optimizing FDFO in terms of AnMBR effluent treatment and OMPs rejection. OMPs rejection was reduced by high water flux as well as low flux decline (i.e., MAP and $\mathrm{KCl}$ ) but also enhanced by membrane scaling (i.e., DAP). Thus, this trade-off between high dilution of draw solution (i.e., high water flux and low flux decline) and high OMPs rejection (i.e., low OMPs forward flux) should be considered in FDFO design and optimization.

\section{Acknowledgements}

This research was supported by funding from the SEED program of King Abdullah University of Science and Technology (KAUST), Saudi Arabia. The help, assistance and support of the Water Desalination and Reuse Center (WDRC) staff are greatly appreciated. 
This study was also partially supported under the ARC Future Fellowship (FT140101208) and University of Technology Sydney chancellor's postdoctoral research fellowship.

\section{References}

[1] F.R. Rijsberman, Water scarcity: Fact or fiction?, Agricultural Water Management, 80 (2006) 5-22.

[2] J. Clay, World Agriculture and the Environment: A Commodity-by-Commodity Guide to Impacts and Practices, Island Press, 2004.

[3] H. Jeong, C. Seong, T. Jang, S. Park, Classification of Wastewater Reuse for Agriculture: A Case Study in South Korea, Irrigation and Drainage, 65 (2016) 76-85.

[4] B.E. Jiménez Cisneros, T. Asano, Water reuse : an international survey of current practice, issues and needs, IWA Pub., London, 2008.

[5] A. Bahri, Managing the Other Side of the Water Cycle: Making Wastewater an Asset, in, Mölnlycke, 2009.

[6] F.a.A.O.o.t.U. Nations, Direct use of municipal wastewater for irrigation, in, Food and Agriculture Organization of the United Nations, Rome, 2016.

[7] S.A. Snyder, P. Westerhoff, Y. Yoon, D.L. Sedlak, Pharmaceuticals, Personal Care Products, and Endocrine Disruptors in Water: Implications for the Water Industry, Environmental Engineering Science, 20 (2003) 449-469.

[8] Environmental Guidelines: Use of Effluent by Irrigation, in, Department of Environment and Conservation (NSW), Sydney, 2004.

[9] D.C. Stuckey, Recent developments in anaerobic membrane reactors, Bioresource Technology, 122 (2012) 137-148.

[10] L. Wang, K.C. Wijekoon, L.D. Nghiem, S.J. Khan, Removal of polycyclic musks by anaerobic membrane bioreactor: Biodegradation, biosorption, and enantioselectivity, Chemosphere, 117 (2014) 722-729.

[11] K.C. Wijekoon, J.A. McDonald, S.J. Khan, F.I. Hai, W.E. Price, L.D. Nghiem, Development of a predictive framework to assess the removal of trace organic chemicals by anaerobic membrane bioreactor, Bioresource Technology, 189 (2015) 391-398. 
[12] C.-H. Wei, C. Hoppe-Jones, G. Amy, T. Leiknes, Organic micro-pollutants' removal via anaerobic membrane bioreactor with ultrafiltration and nanofiltration, Journal of Water Reuse and Desalination, 6 (2016) 362-370.

[13] V.M. Monsalvo, J.A. McDonald, S.J. Khan, P. Le-Clech, Removal of trace organics by anaerobic membrane bioreactors, Water Research, 49 (2014) 103-112.

[14] Y. Kiso, Y. Sugiura, T. Kitao, K. Nishimura, Effects of hydrophobicity and molecular size on rejection of aromatic pesticides with nanofiltration membranes, Journal of Membrane Science, 192 (2001) 1-10.

[15] K. Kimura, S. Toshima, G. Amy, Y. Watanabe, Rejection of neutral endocrine disrupting compounds (EDCs) and pharmaceutical active compounds (PhACs) by RO membranes, Journal of Membrane Science, 245 (2004) 71-78.

[16] M. Xie, L.D. Nghiem, W.E. Price, M. Elimelech, Comparison of the removal of hydrophobic trace organic contaminants by forward osmosis and reverse osmosis, Water Research, 46 (2012) 2683-2692.

[17] T.Y. Cath, A.E. Childress, M. Elimelech, Forward osmosis: Principles, applications, and recent developments, Journal of Membrane Science, 281 (2006) 70-87.

[18] S. Phuntsho, H.K. Shon, T. Majeed, I. El Saliby, S. Vigneswaran, J. Kandasamy, S. Hong, S. Lee, Blended Fertilizers as Draw Solutions for Fertilizer-Drawn Forward Osmosis Desalination, Environmental Science \& Technology, 46 (2012) 4567-4575.

[19] S. Phuntsho, H.K. Shon, S. Hong, S. Lee, S. Vigneswaran, A novel low energy fertilizer driven forward osmosis desalination for direct fertigation: Evaluating the performance of fertilizer draw solutions, Journal of Membrane Science, 375 (2011) 172181.

[20] M. Xie, M. Zheng, P. Cooper, W.E. Price, L.D. Nghiem, M. Elimelech, Osmotic dilution for sustainable greenwall irrigation by liquid fertilizer: Performance and implications, Journal of Membrane Science, 494 (2015) 32-38.

[21] S. Phuntsho, S. Hong, M. Elimelech, H.K. Shon, Forward osmosis desalination of brackish groundwater: Meeting water quality requirements for fertigation by integrating nanofiltration, Journal of Membrane Science, 436 (2013) 1-15.

[22] S. Phuntsho, J.E. Kim, M.A.H. Johir, S. Hong, Z. Li, N. Ghaffour, T. Leiknes, H.K. Shon, Fertiliser drawn forward osmosis process: Pilot-scale desalination of mine impaired water for fertigation, Journal of Membrane Science, 508 (2016) 22-31. 
[23] S. Sahebi, S. Phuntsho, J. Eun Kim, S. Hong, H. Kyong Shon, Pressure assisted fertiliser drawn osmosis process to enhance final dilution of the fertiliser draw solution beyond osmotic equilibrium, Journal of Membrane Science, 481 (2015) 63-72.

[24] S. Zou, Z. He, Enhancing wastewater reuse by forward osmosis with self-diluted commercial fertilizers as draw solutes, Water Research, 99 (2016) 235-243.

[25] Y. Kim, L. Chekli, W.-G. Shim, S. Phuntsho, S. Li, N. Ghaffour, T. Leiknes, H.K. Shon, Selection of suitable fertilizer draw solute for a novel fertilizer-drawn forward osmosis-anaerobic membrane bioreactor hybrid system, Bioresource Technology, 210 (2016) 26-34.

[26] L. Chekli, Y. Kim, S. Phuntsho, S. Li, N. Ghaffour, T. Leiknes, H.K. Shon, Evaluation of fertilizer-drawn forward osmosis for sustainable agriculture and water reuse in arid regions, Journal of Environmental Management, 187 (2017) 137-145.

[27] Y. Kim, S. Lee, H.K. Shon, S. Hong, Organic fouling mechanisms in forward osmosis membrane process under elevated feed and draw solution temperatures, Desalination, 355 (2015) 169-177.

[28] J.R. McCutcheon, M. Elimelech, Influence of membrane support layer hydrophobicity on water flux in osmotically driven membrane processes, Journal of Membrane Science, 318 (2008) 458-466.

[29] C.-H. Wei, M. Harb, G. Amy, P.-Y. Hong, T. Leiknes, Sustainable organic loading rate and energy recovery potential of mesophilic anaerobic membrane bioreactor for municipal wastewater treatment, Bioresource Technology, 166 (2014) 326-334.

[30] S. Lee, Y. Kim, A.S. Kim, S. Hong, Evaluation of membrane-based desalting processes for RO brine treatment, Desalination and Water Treatment, (2015) 1-8.

[31] S. Phuntsho, F. Lotfi, S. Hong, D.L. Shaffer, M. Elimelech, H.K. Shon, Membrane scaling and flux decline during fertiliser-drawn forward osmosis desalination of brackish groundwater, Water Research, 57 (2014) 172-182.

[32] M. Alidina, C. Hoppe-Jones, M. Yoon, A.F. Hamadeh, D. Li, J.E. Drewes, The occurrence of emerging trace organic chemicals in wastewater effluents in Saudi Arabia, Science of The Total Environment, 478 (2014) 152-162.

[33] B. Kim, S. Lee, S. Hong, A novel analysis of reverse draw and feed solute fluxes in forward osmosis membrane process, Desalination, 352 (2014) 128-135. 
[34] C. Kim, S. Lee, H.K. Shon, M. Elimelech, S. Hong, Boron transport in forward osmosis: Measurements, mechanisms, and comparison with reverse osmosis, Journal of Membrane Science, 419-420 (2012) 42-48.

[35] M. Xie, W.E. Price, L.D. Nghiem, Rejection of pharmaceutically active compounds by forward osmosis: Role of solution $\mathrm{pH}$ and membrane orientation, Separation and Purification Technology, 93 (2012) 107-114.

[36] Y.C. Woo, Y. Kim, W.-G. Shim, L.D. Tijing, M. Yao, L.D. Nghiem, J.-S. Choi, S.-H. Kim, H.K. Shon, Graphene/PVDF flat-sheet membrane for the treatment of RO brine from coal seam gas produced water by air gap membrane distillation, Journal of Membrane Science, 513 (2016) 74-84.

[37] Y.C. Woo, L.D. Tijing, M.J. Park, M. Yao, J.-S. Choi, S. Lee, S.-H. Kim, K.-J. An, H.K. Shon, Electrospun dual-layer nonwoven membrane for desalination by air gap membrane distillation, Desalination.

[38] A. Achilli, T.Y. Cath, A.E. Childress, Selection of inorganic-based draw solutions for forward osmosis applications, Journal of Membrane Science, 364 (2010) 233-241.

[39] M.M. Pendergast, A.K. Ghosh, E.M.V. Hoek, Separation performance and interfacial properties of nanocomposite reverse osmosis membranes, Desalination, 308 (2013) 180185.

[40] S. Kaur, D. Rana, T. Matsuura, S. Sundarrajan, S. Ramakrishna, Preparation and characterization of surface modified electrospun membranes for higher filtration flux, Journal of Membrane Science, 390-391 (2012) 235-242.

[41] Y.C. Woo, J.J. Lee, L.D, Tijing, H.K. Shon, M. Yao, H.-S. Kim, Characteristics of membrane fouling by consecutive chemical cleaning in pressurized ultrafiltration as pretreatment of seawater desalination, Desalination, 369 (2015) 51-61.

[42] E. Ariyanto, T.K. Sen, H.M. Ang, The influence of various physico-chemical process parameters on kinetics and growth mechanism of struvite crystallisation, Advanced Powder Technology, 25 (2014) 682-694.

[43] J.R. McCutcheon, M. Elimelech, Influence of concentrative and dilutive internal concentration polarization on flux behavior in forward osmosis, Journal of Membrane Science, 284 (2006) 237-247.

[44] N.Y. Yip, A. Tiraferri, W.A. Phillip, J.D. Schiffman, M. Elimelech, High Performance Thin-Film Composite Forward Osmosis Membrane, Environmental Science \& Technology, 44 (2010) 3812-3818. 
[45] W. Fam, S. Phuntsho, J.H. Lee, H.K. Shon, Performance comparison of thin-film composite forward osmosis membranes, Desalination and Water Treatment, 51 (2013) 6274-6280.

[46] M.-J. Corbatón-Báguena, S. Álvarez-Blanco, M.-C. Vincent-Vela, Salt cleaning of ultrafiltration membranes fouled by whey model solutions, Separation and Purification Technology, 132 (2014) 226-233.

[47] S. Lee, M. Elimelech, Salt cleaning of organic-fouled reverse osmosis membranes, Water Research, 41 (2007) 1134-1142.

[48] B. Mi, M. Elimelech, Organic fouling of forward osmosis membranes: Fouling reversibility and cleaning without chemical reagents, Journal of Membrane Science, 348 (2010) 337-345.

[49] S. Srinivasan, T. Chi, Effect of imperfect salt rejection on concentration polarization in reverse osmosis systems, Desalination, 13 (1973) 287-301.

[50] M. Xie, L.D. Nghiem, W.E. Price, M. Elimelech, Relating rejection of trace organic contaminants to membrane properties in forward osmosis: Measurements, modelling and implications, Water Research, 49 (2014) 265-274.

[51] R. Valladares Linares, V. Yangali-Quintanilla, Z. Li, G. Amy, Rejection of micropollutants by clean and fouled forward osmosis membrane, Water Research, 45 (2011) 6737-6744.

[52] S. Kim, S. Lee, E. Lee, S. Sarper, C.-H. Kim, J. Cho, Enhanced or reduced concentration polarization by membrane fouling in seawater reverse osmosis (SWRO) processes, Desalination, 247 (2009) 162-168.

[53] E.M.V. Hoek, M. Elimelech, Cake-Enhanced Concentration Polarization: A New Fouling Mechanism for Salt-Rejecting Membranes, Environmental Science \& Technology, 37 (2003) 5581-5588.

[54] Y.S. Polyakov, A.L. Zydney, Ultrafiltration membrane performance: Effects of pore blockage/constriction, Journal of Membrane Science, 434 (2013) 106-120. 


\section{Highlights}

- Performance of FDFO was evaluated in terms of flux decline and OMPs removal.

- Flux decline was varied with fertilizer properties and operation conditions.

- OMPs transport was strongly influenced by FDFO fouling behaviour.

- DAP showed lower OMPs flux and higher flux decline due to struvite scaling.

- Osmotic backwashing effectively recovered water flux in AL-DS mode.

\section{Graphical abstract}




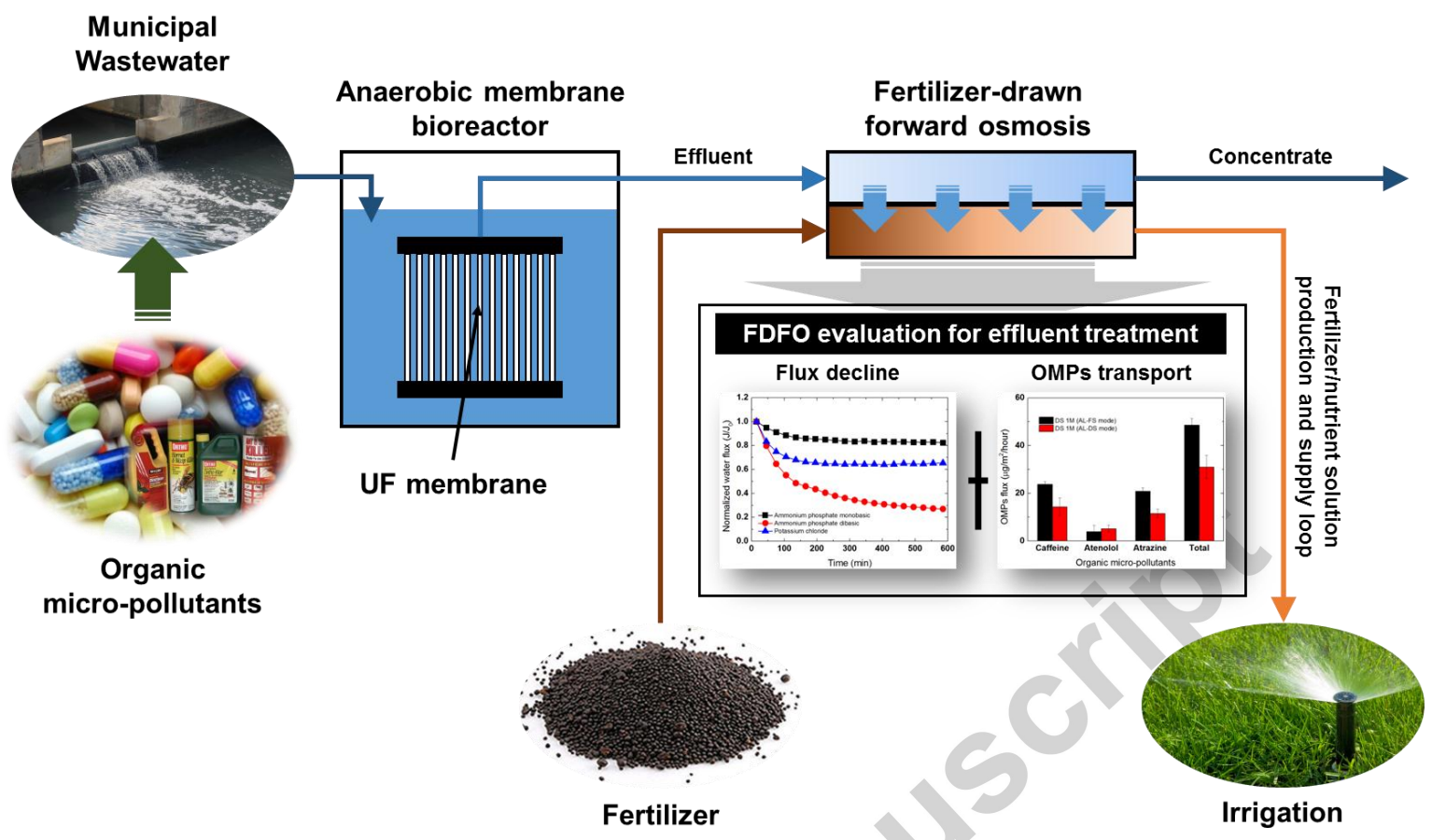

